\title{
Propagation of alpha-synuclein pathology: hypotheses, discoveries, and yet unresolved questions from experimental and human brain studies
}

\author{
Toshiki Uchihara ${ }^{1} \cdot$ Benoit I. Giasson $^{2}$
}

Received: 3 July 2015 / Revised: 15 September 2015 / Accepted: 26 September 2015 / Published online: 7 October 2015

(C) The Author(s) 2015. This article is published with open access at Springerlink.com

\begin{abstract}
Progressive aggregation of alpha-synuclein $(\alpha \mathrm{S})$ through formation of amorphous pale bodies to mature Lewy bodies or in neuronal processes as Lewy neurites may be the consequence of conformational protein changes and accumulations, which structurally represents "molecular template". Focal initiation and subsequent spread along anatomically connected structures embody "structural template". To investigate the hypothesis that both processes might be closely associated and involved in the progression of $\alpha \mathrm{S}$ pathology, which can be observed in human brains, $\alpha \mathrm{S}$ amyloidogenic precursors termed "seeds" were experimentally injected into the brain or peripheral nervous system of animals. Although these studies showed that $\alpha \mathrm{S}$ amyloidogenic seeds can induce $\alpha \mathrm{S}$ pathology, which can spread in the nervous system, the findings are still not unequivocal in demonstrating predominant transsynaptic or intraneuronal spreads either in anterograde or retrograde directions. Interpretation of some of these studies is further complicated by
\end{abstract}

Electronic supplementary material The online version of this article (doi:10.1007/s00401-015-1485-1) contains supplementary material, which is available to authorized users.

Toshiki Uchihara

uchihara-ts@igakuken.or.jp

$\triangle$ Benoit I. Giasson

bgiasson@ufl.edu

1 Laboratory of Structural Neuropathology, Tokyo Metropolitan Institute of Medical Science, 2-1-6 Kamikitazawa, Setagaya-ku, Tokyo 156-8506, Japan

2 Department of Neuroscience, Center for Translational Research in Neurodegenerative Disease, McKinght Brain Institute, University of Florida, 1275 Center Drive, PO Box 100159, Gainesville, FL 32610-0159, USA other concurrent aberrant processes including neuroimmune activation, injury responses and/or general perturbation of proteostasis. In human brain, $\alpha \mathrm{S}$ deposition and neuronal degeneration are accentuated in distal axon/synapse. Hyperbranching of axons is an anatomical commonality of Lewy-prone systems, providing a structural basis for abundance in distal axons and synaptic terminals. This neuroanatomical feature also can contribute to such distal accentuation of vulnerability in neuronal demise and the formation of $\alpha \mathrm{S}$ inclusion pathology. Although retrograde progression of $\alpha \mathrm{S}$ aggregation in hyperbranching axons may be a consistent feature of Lewy pathology, the regional distribution and gradient of Lewy pathology are not necessarily compatible with a predictable pattern such as upward progression from lower brainstem to cerebral cortex. Furthermore, "focal Lewy body disease" with the specific isolated involvement of autonomic, olfactory or cardiac systems suggests that spread of $\alpha \mathrm{S}$ pathology is not always consistent. In many instances, the regional variability of Lewy pathology in human brain cannot be explained by a unified hypothesis such as transsynaptic spread. Thus, the distribution of Lewy pathology in human brain may be better explained by variable combinations of independent focal Lewy pathology to generate "multifocal Lewy body disease" that could be coupled with selective but variable neuroanatomical spread of $\alpha S$ pathology. More flexible models are warranted to take into account the relative propensity to develop Lewy pathology in different Lewy-prone systems, even without interconnections, compatible with the expanding clinicopathological spectra of Lewy-related disorders. These revised models are useful to better understand the mechanisms underlying the variable progression of Lewy body diseases so that diagnostic and therapeutic strategies are improved. 
Keywords Focal Lewy body disease · Hyperbranching axons $\cdot$ Molecular template $\cdot$ Structural template . Gradient $\cdot$ Alpha-synuclein

\section{Introduction}

Eosinophilic inclusions with halo, now known as Lewy bodies, (LBs) were identified by Friedrich Heinrich Lewy in the dorsal motor nucleus of vagus $(\mathrm{dmX})$ and substantia innominata in the brains of patients with Parkinson disease (PD) [43, 69]. Initially, their presence in the substantia nigra $(\mathrm{SN})$ was not readily recognized probably because they were less frequent in SN and their relevance to PD had not been established until Konstantin Nikolaevich Tretiakoff identified a consistent association between nigral degeneration with LBs as a pathological substrate for PD [73, 114]. However, it remained unexplained how these inclusions at multiple brain regions were related to characteristic motor deficits of PD until dopaminergic deficit of nigrostriatal system was identified as a major mechanism of PD [85, 164], largely involved in the motor presentation of PD. This nigra-centered explanation was reinforced after dramatic improvement by replacement therapy with levodopa $[6,39]$.

Histochemical identification of Lewy pathology was improved by silver impregnations [175] and later by ubiquitin or neurofilament immunohistochemistry (IHC) [71]. Ultimately, IHC for alpha-synuclein $(\alpha \mathrm{S})$, which is its major molecular component [168], is the most sensitive and specific gold standard to detect various types of Lewy pathologies. Amorphous early $\alpha \mathrm{S}$ deposits in the neuronal cytoplasm, known as pale body and pale neurites [92], suggests that initial amorphous $\alpha \mathrm{S}$ deposits may evolve progressively into more aggregated typical LBs.

In addition to this progressive aggregation of $\alpha \mathrm{S}$ in the neuronal cytoplasm and neurites, the identification of LBs in the cerebral cortices in patients with atypical dementia [102, $103,141]$ and in peripheral tissues [180] raised attention for their more extensive distribution that might explain other related clinical manifestations. Even after the identification of $\alpha \mathrm{S}$ as a major component of LBs, however, it remains to be clarified how (when and where) LBs are formed [22, 45]. Because Lewy pathology is more abundant in the lower brainstem in a majority of cases, it is generally assumed as if Lewy pathology is initiated in the lower brainstem and spreads into upper brainstem [21, 45]. This idea led to a hypothesis that conformational change of $\alpha \mathrm{S}$ to form aggregates might have templated itself to spread along neuroanatomical connections, which may be similar to prion disease, at least partly. Because this unified hypothesis is highly convenient and attractive to explain both local molecular change of $\alpha \mathrm{S}$ as "a molecular template" and its stereotyped spread as "a structural template", this combination is now enjoying the initial honeymoon of a happy marriage, when everything is usually considered in favor of this hypothesis. To make this marriage profoundly fruitful or at least acceptably fruitful even after the honeymoon period, some skepticism may be useful to recognize its potential pitfalls, possible misunderstandings or misinterpretations, if any.

In this review, we will first discuss the molecular basis for some of the animal experimental studies that may support a conformational templating of $\alpha \mathrm{S}$ protein, as a pivotal mechanism involved in neuroanatomical spread of $\alpha \mathrm{S}$ pathology. However, we also consider how this simplistic mechanistic view does NOT fully take into account the global complexities of induced experimental paradigms and the variable presentations of human neuropathology. We explore the additional biological changes and unique neuroanatomical properties associated with Lewy pathology that might provide alternative explanations for its distribution and clinical presentations. Indeed, specific neuroanatomical and morphological properties of select neuronal populations combined with alterations in multiple synergistic pathogenic mechanisms likely explain the variable clinical presentation of neurodegenerative diseases associated with Lewy pathology. $\alpha \mathrm{S}$ pathology can often present with concomitant cerebral Amyloid $\beta$-protein $(\mathrm{A} \beta)$, tau and/or TAR DNA-binding protein-43 (TDP-43) inclusion pathology which could influence both the formation of $\alpha \mathrm{S}$ pathology and the clinical findings in some patients [86, 104], but these topics are beyond the scope of this review.

\section{Molecular template (experimental considerations)}

\section{Self-templating of $\alpha \mathrm{S}$ promoting in vitro amyloid aggregate formation}

The in vitro polymerization of soluble monomeric $\alpha \mathrm{S}$ into fibrils that are biochemically, morphologically and structurally similar to those in human pathological inclusions is associated with a profound transformation in secondary structure from natively, unfolded random coil to predominantly $\beta$-pleated sheet $[35,36,66,79,138,166]$. $\alpha S$ folded into $\beta$-pleated sheets is permissive to polymerizing into $\sim 10$-nm-wide unbranched fibrils that have typical amyloidogenic properties (Fig. 1) [36, 67, 68, 166, 186]. In vivo, $\alpha \mathrm{S}$ is predominantly a neuronal soluble, unfolded protein $[28,60,87]$, but a significant proportion is loosely associated with various cellular membranes driven by its ability to form amphipathic $\alpha$-helical structures $[42,87,98,196]$. Therefore, in its naïve state(s), $\alpha \mathrm{S}$ is not primed to aggregate into amyloid-type inclusions.

The in vitro polymerization of soluble $\alpha S$ into amyloid fibrils is characterized by a lag phase followed by a 

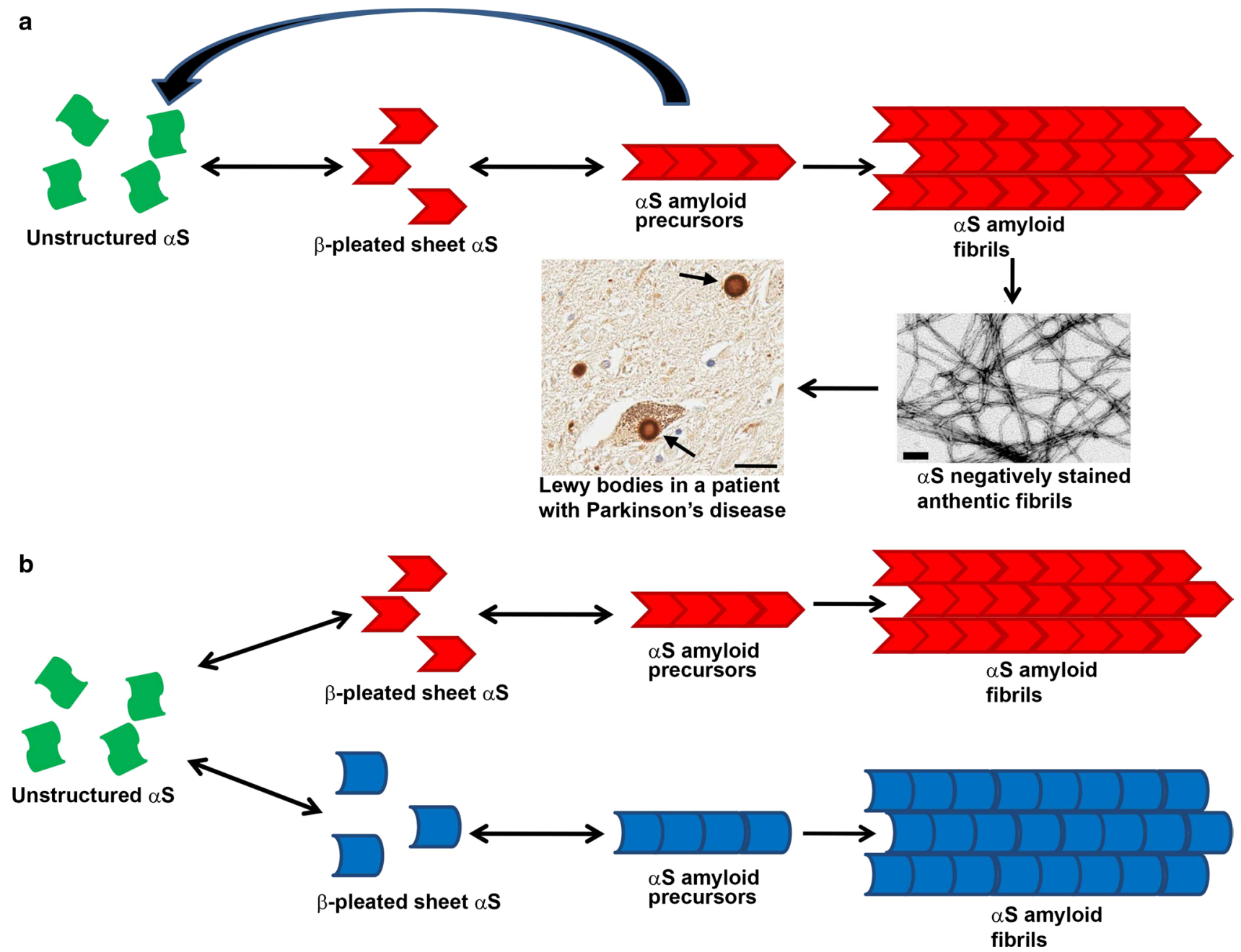

Fig. 1 Schematic representation of the molecular changes resulting in $\alpha \mathrm{S}$ pathological inclusions. a $\alpha \mathrm{S}$ is naturally predominantly an unstructured, soluble protein (green shapes) that can randomly convert to acquire a $\beta$-pleated sheet conformation (red shapes). Once in this conformation $\alpha \mathrm{S}$ can polymerize into longer amyloid precursor units and eventually fibrils (shown as negative stained $\alpha \mathrm{S}$ fibrils assembled in vitro and observed by electron microscopy; bar

rapid increase in fibril formation that can be promoted by increasing $\alpha \mathrm{S}$ protein concentration [118, 138, 177, 191]. Therefore, it appears that the formation of a critical amount of $\alpha \mathrm{S}$ amyloid precursors that may stochastically form in solution and is favored by increased protein concentration, which may also stabilize these structures due to increased protein interactions, is an important limiting step in driving $\alpha \mathrm{S}$ amyloid formation. Experimentally, the simple addition of preformed fibrillar $\alpha \mathrm{S}$ precursors (PFSPs), also termed "seeding" or "nucleation", to overcome this threshold can rapidly promote the recruitment of unstructured $\alpha \mathrm{S}$ molecules into amyloidogenic permissive structure resulting into a synergistic formation of amyloid fibrils (Fig. 1) [191]. This in vitro process of using PFSPs to convert
$100 \mathrm{~nm}$ ) that coalesce to form pathological inclusions (shown as Lewy bodies: LBs, staining with an anti- $\alpha \mathrm{S}$ antibody; bar $25 \mu \mathrm{m})$. b $\alpha S$ can potentially polymerize into amyloid precursor units and amyloidogenic fibrils that at the molecular level have subtle conformational differences (red shapes versus blue shapes) and these are not compatible for co-polymerizing resulting in a "strain"-like specific polymers

normal $\alpha \mathrm{S}$ into amyloid precipitating the formation of mature pathological inclusions has been termed "conformational templating" and provides an interesting model that could explain, at least in part, the spread of $\alpha \mathrm{S}$ pathology that tracks with progression of neurodegenerative process in human brains.

\section{$\alpha \mathrm{S}$ mutants accelerating or decelerating aggregation}

Six missense mutations in the $\alpha \mathrm{S}$ gene, SNCA, resulting in six different amino acid substitutions (A30P, E46K, H50Q, G51D, A53T, and A53E) have been identified that can cause PD with or without additional clinical features such as dementia reflecting a more widespread presentation 
of $\alpha \mathrm{S}$ inclusion pathology typical of dementia with LBs (DLB) $[5,96,107,116,145,150,151,194]$. In addition, short chromosomal duplications or trisomies containing the SCNA gene, plus relatively short flanking regions on chromosome 4, can also result in PD or DLB [31, 56, 167], indicating that a $50 \%$ increase in the expression of $\alpha \mathrm{S}$ is sufficient to cause these disorders. Genetic alternations resulting in increased $\alpha \mathrm{S}$ expression are consistent with the notion described above that a higher abundance of $\alpha \mathrm{S}$ can lead to a greater stochastic formation of $\alpha$ S PFSPs followed by conformational templating resulting in the spread of $\alpha S$ pathology. Alternatively, increased $\alpha \mathrm{S}$ expression could also increase the focal formation of $\alpha \mathrm{S}$ pathology with distribution perhaps reflecting selective vulnerability.

Consistent with conformational templating playing an important role in the spread of $\alpha \mathrm{S}$ pathology, the A53T, $\mathrm{H} 50 \mathrm{Q}$ and $\mathrm{E} 46 \mathrm{~K} \alpha \mathrm{S}$ mutations have consistently been shown to increase the rate of self-aggregation by these mutants [33, 35, 61, 67, 72, 95, 118, 138, 158]. While some reports suggest that $\mathrm{A} 30 \mathrm{P} \alpha \mathrm{S}$ forms amyloid fibrils more slowly than wild-type (WT) $\alpha \mathrm{S}$ [37], this finding has not been consistently observed by others [67, 138]. In addition, the A30P mutation appears to affect $\alpha \mathrm{S}$ independently of protein aggregation, probably by partially impairing the ability of $\alpha \mathrm{S}$ to bind to brain vesicles, likely due to a decreased likelihood to form $\alpha$-helices [30, 52]. However, both the A53E and G51D $\alpha \mathrm{S}$ mutations have been shown to significantly reduce the intrinsic propensity of $\alpha \mathrm{S}$ to polymerize and aggregate, hence in principle, lowering amyloid transmissibility [55, 62, 157, 158], despite still causing early-onset PD with robust $\alpha \mathrm{S}$ pathology [96, 116, 145]. Collectively, there is no simple explanation for how all the known missense mutations in $\alpha \mathrm{S}$ result in PD and their divergent effects on in vitro aggregate formation suggest that conformational templating cannot solely account for disease progression.

\section{Cellular models of $\alpha \mathrm{S}$ release, uptake, transfer and inclusion formation}

Many cell culture studies have demonstrated that several non-mutually exclusive mechanisms including release by exocytosis $[109,121]$, uptake by various endocytosis mechanisms [1, 110, 112, 171], release/uptake of exosomes [41, 53], and release due to cell death could be involved in the intercellular transmission of $\alpha \mathrm{S}$ aggregates. Using transfection reagents to drive membrane permeability, it was shown that the entry of a small amount of exogenous PFSPs into cells expressing $\alpha \mathrm{S}$ is sufficient to efficiently induce endogenously expressed $\alpha \mathrm{S}$ to form mature cytoplasmic amyloidogenic inclusions [126, 140, 188]. Thereafter, it was shown that the simple addition of extracellular PFSPs to primary neurons may be able to induce the formation of intracellular $\alpha \mathrm{S}$ inclusions without the addition of other reagents [179], with the caveat that these studies were predominantly documented by immunostaining with antibody pSer129/81A (see below). Utilizing microfluidic devices to separate the soma and axonal projections from separate but adjacent and synapsed primary neuronal populations, it was shown that following neuronal uptake, PFSPs can move by both anterograde and retrograde axonal transport but that synaptic contact is not required for transfer between neurons $[58,179]$.

Using recombinant adeno-associated viral (rAAV)mediated $\alpha \mathrm{S}$ overexpression in mouse primary neuronalglial culture, it was demonstrated that exposure to exogenous PFSPs could efficiently induce intracellular $\alpha \mathrm{S}$ inclusion pathology in cells overexpressing $\alpha \mathrm{S}$, and that this inclusion formation occurred in a fashion that was consistent with conformational templating since the morphology of the induced $\alpha \mathrm{S}$ inclusions could be dictated by the type of PFSPs added [163]. Collectively, these cell culture studies have shown that under defined conditions conformational templating of $\alpha \mathrm{S}$ leading to inclusion formation can occur and they have provided insights into the cellular mechanisms that might be involved. However, it should also be considered that the concentrations of PFSPs used for most of these studies are beyond the physiological levels of exogenous $\alpha \mathrm{S}$.

\section{Anti-phosphorylated Ser129 $\alpha$ S antibodies can label other phospho-proteins and $\alpha \mathrm{S}$ phosphorylation is induced by stress}

Although phosphorylation of $\alpha \mathrm{S}$ at Ser129 can be a robust marker of $\alpha \mathrm{S}$ inclusion pathology (Suppl. Figure 1) as this residue is highly phosphorylated in human pathological inclusions ( $\sim 90 \%$ phosphorylated in inclusions versus $\sim 4 \%$ phosphorylated in total brain $\alpha \mathrm{S})$ [3, 24, 59, 187], phosphorylated Ser 129 (pSer129) immunoreactivity on histological sections should not be equated to the formation of $\alpha \mathrm{S}$ inclusion without validation with other techniques. First, most pSer129 $\alpha \mathrm{S}$ antibodies cross-react with other phosphorylated proteins. For example, $\alpha \mathrm{S}$ pSer 129/81A antibody that has been used in many studies can strongly cross-react with phosphorylated low-molecule mass neurofilament subunits (NFL) and can give the false impression of $\alpha S$ inclusion pathology (Suppl. Figure 2) [162]. Not all $\alpha \mathrm{S}$ pSer 129 antibodies that have been used in other studies also cross-react with phosphorylated NFL, but antibodies such as MJF-R13(8-8) can cross-react with other non- $\alpha \mathrm{S}$ phosphorylated proteins (Suppl. Figures 1, 2). These facts highlight the need for well-characterized pSer129 $\alpha$ S antibodies (e.g. as shown in Suppl. Figures 1,2), especially for immunostaining studies. It is not surprising that antibodies to phosphorylated $\alpha \mathrm{S}$ Ser129 can cross-react with other 
phospho-proteins since this epitope can be phosphorylated by multiple kinases, such as casein kinases and polo-like kinases [24], and thus this phospho-epitope has a high level of homology to many phosphorylation sites in other proteins that are also recognized and phosphorylated by these kinases. Second, many cellular stresses or insults can greatly increase the phosphorylation state of many proteins, including $\alpha S$ Ser129, without inducing inclusion formation [187]. Therefore, in human or experimental animal studies, increased staining for $\alpha \mathrm{S}$ Ser129 should not be directly equated to inclusion formation without validation with other non-phospho-specific $\alpha \mathrm{S}$ antibodies or other histological analyses.

\section{Rodent studies of induction and spread of $\alpha \mathrm{S}$ inclusion pathology}

In the next sections, we discuss the studies utilizing $\alpha \mathrm{S}$ transgenic mice and WT (i.e., non-transgenic) mice or rats that have been conducted to try to provide evidence that conformational templating of $\alpha \mathrm{S}$ aggregates can occur in vivo, but we also critically highlight some of the technical shortcoming and the complexity in assessing the mechanisms involved in promoting $\alpha \mathrm{S}$ inclusion pathology in these studies. In fact, some of the findings from these studies also support that other mechanisms can also be important in driving the spread of $\alpha \mathrm{S}$ pathology. Comparing the findings from these studies, utilizing $\alpha \mathrm{S}$ transgenic and WT mice also provides important clues to biological barriers that are likely important to naturally suppress the spread of $\alpha \mathrm{S}$ pathology. However, it is also important to note that the direct comparison of the findings from different groups can be complicated by differences in experimental conditions, for example the type of PFSPs used, which can be affected by many factors including the sonication conditions used for the preparations.

$\alpha S$ transgenic mouse models most commonly used

for induction or transmission of $\alpha S$ pathology

Most of the $\alpha \mathrm{S}$ transgenic mouse lines that were used to study transmission of $\alpha \mathrm{S}$ pathological entities or $\alpha \mathrm{S}$ conformational templating mechanisms were identically created with the human $\alpha \mathrm{S}$ cDNAs cloned into an expression vector where transgenic expression is driven by the mouse prion promoter [19]. Three of these transgenic mouse lines expressing WT human $\alpha \mathrm{S}$ (line M20), A53T human $\alpha \mathrm{S}$ (line M83) or E46K human $\alpha \mathrm{S}$ (line M47) have been used. These $\alpha \mathrm{S}$ transgenic mice predominantly express human $\alpha \mathrm{S}$ throughout central nervous system (CNS) neurons [54, 64] as would be expected from expression driven by mouse prion protein promoter [19]. The expression levels in all three transgenic mouse lines are similar but the expression in M20 $\alpha \mathrm{S}$ mice is modestly higher than for the M83 $\alpha \mathrm{S}$ mice, while the expression in M47 $\alpha \mathrm{S}$ mice is slightly lower [54, 64]. Importantly, as the mouse prion protein is not exclusively expressed in neurons, the expression driven by the mouse prion protein promoter occurs not only in CNS neurons, but also at substantial levels in glial cells especially in astrocytes $[117,181]$.

Native homozygous $\mathrm{M} 83^{+/+} \alpha \mathrm{S}$ mice normally develop a late-onset (8-15 months of age) severe motor phenotype leading to death that results from the formation of neuronal $\alpha \mathrm{S}$ amyloidogenic inclusions predominantly throughout the spinal cord, brain stem, thalamus and midbrain areas, and with some $\alpha \mathrm{S}$ inclusions in the motor cortex [64]. Remarkably, dopaminergic nigral neurons are resilient to the formation of $\alpha S$ inclusions in these mice despite being surrounded by neurons with $\alpha \mathrm{S}$ inclusions [64]. In addition, detailed analyses of the initial presentation of $\alpha \mathrm{S}$ inclusions throughout the neuroaxis in these mice, before they are symptomatic, showed that they randomly appear without any clustering or direct evident of general spread [54]. This finding is more consistent with concurrent multifocal formation of $\alpha \mathrm{S}$ inclusions with variable spreads as we suggest could explain some of the presentation of Lewy pathology in human brains (see below). Native hemizygous ${\mathrm{M} 83^{+/-}}_{\mathrm{S}} \mathrm{S}$ mice can also develop similar pathologies and phenotype but these are delayed to later than 22 months of age. Native homozygous $\mathrm{M} 20^{+/+}$or hemizygous $\mathrm{M} 20^{+/-}$ $\alpha \mathrm{S}$ mice do not develop any overt motor dysfunction or the presentation of $\alpha \mathrm{S}$ pathology throughout their normal lifespan [54, 64]. Homozygous $\mathrm{M}_{4} 7^{+/+} \alpha \mathrm{S}$ mice naturally develop a similar phenotype and neuroanatomical distribution of $\alpha \mathrm{S}$ inclusions as the M83 $\alpha \mathrm{S}$ mice but with a later onset ( $>15$ months) and with morphologically distinct $\alpha \mathrm{S}$ inclusions which are more round and compact reminiscent of human inclusions [54].

\section{Brain extract injection in the cerebrum of $\alpha S$ transgenic mice to model pathogenic transmission}

In studies aimed at demonstrating that $\alpha \mathrm{S}$ pathology could be transmitted, young $\mathrm{M} 83^{+/+}$or $\mathrm{M} 83^{+/-} \alpha \mathrm{S}$ mice were injected in various brain regions with CNS extracts containing $\alpha \mathrm{S}$ aggregates from older motor impaired $\mathrm{M} 83^{+/+}$ $\alpha \mathrm{S}$ mice. These injections resulted in both an earlier presentation of $\alpha \mathrm{S}$ pathology and motor phenotype [13, 125, $137,184]$, and this induction was reportedly not observed in one set of $\mathrm{M}^{2} 3^{+/+} \alpha \mathrm{S}$ mice injected with brain extracts generated from healthy M83 $\alpha \mathrm{S}$ mice [137]. However, it is important to point out that these studies have not unequivocally demonstrated that $\alpha \mathrm{S}$ itself was the inducer of pathology being transmitted as CNS extracts from diseased mice would contain potential inducers of many pathological alterations including elevation in gliosis and various 
cellular injury response activators. To definitely demonstrate that the induction of pathology was specifically due to transmission of $\alpha \mathrm{S}$ molecules, a key experimental control usually includes $\alpha \mathrm{S}$ immuno-depletion where the $\alpha \mathrm{S}$ present in the sample is removed by antibody absorption. Intracerebral injection of brain lysates from patients with multiple system atrophy (MSA) was also shown to induce $\alpha \mathrm{S}$ inclusion pathology in $\mathrm{M} 83^{+/-} \alpha \mathrm{S}$ mice [184], but again $\alpha \mathrm{S}$ immune depletion from these extracts was not performed to demonstrate that the presence of $\alpha \mathrm{S}$ aggregates was responsible for inducing these changes. In addition, the pattern of $\alpha \mathrm{S}$ pathology induced in these studies was typical of the pattern observed in aging M83 $\alpha \mathrm{S}$ mice such that the distribution did not appear to follow progression from the injection site [184] or that typically observed in MSA brain. Because clinicopathological differences between Lewy-related cytopathology and MSA are now well recognized [132], it remains to be clarified whether the shared concept of "synucleinopathy" between MSA and PD/DLB is corroborated by such models. Similar experimental passaging studies using CNS extracts from diseased mice into younger health $\alpha \mathrm{S}$ transgenic mice to initiate earlier motor phenotype and $\alpha \mathrm{S}$ pathology were also recently shown using $\alpha \mathrm{S}$ transgenic mice with expression driven by the Thy-1 promoter [165]. Collectively, these studies showed that CNS extracts from $\alpha \mathrm{S}$ mice or human brains that are undergoing neurodegeneration can induce pathology in $\alpha \mathrm{S}$ overexpressing mice that are inherently primed as internal template but it still remains to be confirmed whether this was due to direct conformational templating by amyloidogenic $\alpha \mathrm{S}$ species and subsequent spatial spread. In addition, these studies heavily relied on pSer129 staining.

\section{Soluble $\alpha S$ or PFSPs injection in the cerebrum of $\alpha S$ transgenic mice to model pathogenic transmission}

A more direct experimental paradigm to try to demonstrate the involvement of $\alpha \mathrm{S}$ conformational templating in the induction and spread of $\alpha S$ is the brain injection of in vitro produced recombinant PFSPs. The cerebral injection of recombinant, exogenous PFSPs can induce the formation of intracellular $\alpha \mathrm{S}$ inclusion pathology in $\mathrm{M} 83^{+/+} \alpha \mathrm{S}$ mice resulting in the typical motor impairments and paralysis characteristic of the phenotype that occurs in these mice with aging [13, 125, 162]. Furthermore, the observed induced $\alpha \mathrm{S}$ pathology was consistent with progression from the brain injection sites used (e.g., hippocampal, cortical or striatal) with the induced brainstem and spinal cord pathology likely reflecting the selective regional vulnerability of these transgenic mice [125, 162]. However, the majority of the white matter staining that was initially reported as an evidence for spread of $\alpha \mathrm{S}$ pathology along white matter tracts [125] was later attributed to the cross-reactivity of the antibody anti-phosphorylated Ser129 (pSer129)/clone 81A with phosphorylated NFL [162].

In similar types of studies, intracerebral injections of PFSPs into adult M $20^{+/-} \alpha \mathrm{S}$ mice also resulted in a robust induction of $\alpha \mathrm{S}$ inclusion pathology that spread over time from the site of injection [160]. However, cerebral injection of the non-amyloidogenic $\Delta 71-82 \alpha \mathrm{S}$ deletion mutant, which under physiological conditions cannot form amyloid fibrils, directly influence the in vitro polymerization of normal $\alpha \mathrm{S}$ or directly induce the seeding of $\alpha \mathrm{S}$ inclusions in cultured cells [66, 126, 163, 189], was able to induce $\alpha \mathrm{S}$ inclusion pathology, albeit less robustly than PFSPs [160]. In addition, the brain injection of PFSPs in adult M $20^{+/-}$ and $\mathrm{M} 83^{+/+} \alpha \mathrm{S}$ mice resulted in the abnormal accumulations of NFL and peripherin [160], a neuronal intermediate filament protein that can be expressed in the CNS as a result of injury response [9]. Furthermore, cerebral injection of PFSPs into $\mathrm{M} 20^{+/-}$or $\mathrm{M} 83^{+/+} \alpha \mathrm{S}$ mice induced the formation of additional protein inclusions immunoreactive for p62/sequestosome, a general marker of inclusion formation, that were not comprised of $\alpha \mathrm{S}$ or NFL suggestive of a more general disruption of proteostasis [160]. Robust gliosis was induced from cerebral PFSP treatment and a significant proportion of the induced $\alpha \mathrm{S}$ inclusion pathology was observed in glial cells especially astrocytes [125, 160], which are rarely observed in human brain with PD. $\alpha \mathrm{S}$ is normally a neuronal protein expressed only at low levels in glia [60, 63, 87-89, 134], so this robust $\alpha \mathrm{S}$ pathology in glial cells likely reflects the ectopic, non-neuronal transgenic expression driven in these cells by the mouse prion protein promoter $[117,181]$. Glial cells, similar to many other types of cells, can uptake and conceivably degrade exogenous PFSPs or amyloidogenic $\alpha$ S released by cells $[108,111,154]$. Therefore, glial cells can normally act as a barrier to the spread of $\alpha S$ pathology if indeed cellular release and reuptake are required (Fig. 2a). However, in $\alpha \mathrm{S}$ transgenic mice created using the mouse prion protein promoter, the ectopic expression of $\alpha \mathrm{S}$ in glial cells, especially in astrocytes can result in a more widespread formation of $\alpha \mathrm{S}$ inclusion pathology, thus exacerbating the spread of pathological inclusion and injury responses (Fig. 2b). In addition, this propagation of $\alpha \mathrm{S}$ inclusion by glial cells does not have to follow neuroanatomical pathways.

For reasons that are still unclear, not every $\alpha \mathrm{S}$ transgenic mouse lines demonstrate vulnerability leading to PFSP-induced $\alpha S$ pathology. In parallel stereotactic cer-

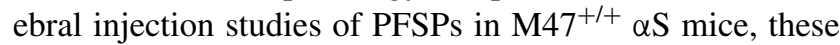
mice were relatively refractory to the spread of $\alpha S$ inclusion pathology induced by PFSPs as $\alpha \mathrm{S}$ inclusions were predominantly observed only at the site of injection [162]. Similar findings was obtained using PFSPs comprised of WT or E46K human $\alpha \mathrm{S}$ demonstrating that this limited induction of $\alpha \mathrm{S}$ was not due to incompatible heterotypic 


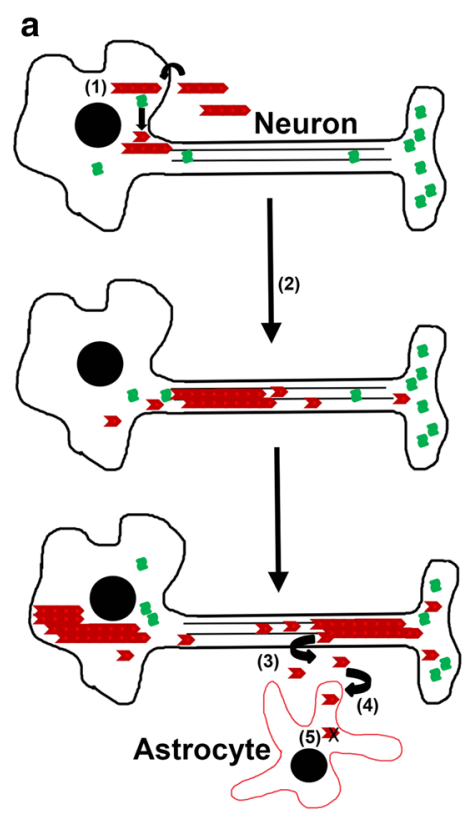

Fig. 2 Diagrammatic representation of the mechanisms that can modulate the spread of $\alpha \mathrm{S}$ inclusion pathology in WT and $\alpha \mathrm{S}$ transgenic mice. a The cytoplasmic entry of PFSPs (red shapes) followed by the interaction with normally unstructured soluble $\alpha \mathrm{S}$ molecules (green shapes) can induce their conversion into $\beta$-pleated sheet structures (1). In this form, $\alpha \mathrm{S}$ can elongate into larger amyloidogenic polymers that coalesce into protein inclusions (2). Some of the amyloidogenic $\alpha \mathrm{S}$ species may be released by neurons into the extracellular

interaction (i.e., cross-species differences) between PFSPs comprised of WT and E46K human $\alpha \mathrm{S}$.

\section{Soluble $\alpha S$ or PFSPs injection in the brain of neonatal $\alpha S$ transgenic mice to model pathogenic transmission}

Similar to the induction of $\alpha \mathrm{S}$ inclusion pathology following the injection of PFSPs in adult $\mathrm{M} 20^{+/-} \alpha \mathrm{S}$ mice, injection of PFSPs in $\mathrm{M}^{2} 0^{+-} \alpha \mathrm{S}$ neonatal mice can induce the formation of $\alpha \mathrm{S}$ inclusion pathology [159]. However, depending on the amount of PFSPs injected, the formation of $\alpha \mathrm{S}$ inclusion pathology can appear only 8 months after the injection of PFSPs [159]. This finding is remarkable since the presence of the injected PFSPs in neonatal brains could only be detected for 2-4 days [159]. Similar to the studies using adult animals, induction of $\alpha \mathrm{S}$ pathology was also observed following the brain injection of $\Delta 71-82 \alpha \mathrm{S}$ in neonatal $\mathrm{M} 20^{+/-} \alpha \mathrm{S}$ mice, although again it was much less robust [159]. Overall, the induction of $\alpha \mathrm{S}$ pathology following the neonatal injection of exogenous $\alpha \mathrm{S}$ in $\mathrm{M} 20^{+-} \alpha \mathrm{S}$ mice was slower, less efficient and delayed compared to similar injections in adult mice which is likely due to the lower expression of murine and human transgenic $\alpha \mathrm{S}$ in neonatal mouse brains [159], but these findings indicate that the initial brain injection of $\alpha \mathrm{S}$ can trigger a space (3), but if uptake occurs by glial cells (e.g., astrocytes) (4) that do not express $\alpha \mathrm{S}$, this extracellular $\alpha \mathrm{S}$ can be terminally degraded (5). b Similarly, in $\alpha \mathrm{S}$ transgenic mice with expression driven by the mouse prion protein promoter, amyloidogenic $\alpha \mathrm{S}$ species can also be released by neurons into the extracellular space and taken up by glial cells. However, due to the ectopic expression of $\alpha \mathrm{S}$ in transgenic glial cells, this uptake can result in $\alpha \mathrm{S}$ inclusion formation that enhances the spread of $\alpha \mathrm{S}$ pathology

slow biological cascade, perhaps partially involving the initial induction of abnormal $\alpha \mathrm{S}$ aggregates and conformational templating. These alterations can then result in the formation of mature $\alpha \mathrm{S}$ inclusions long after the initial insult. Therefore, $\alpha \mathrm{S}$ inclusion formation can be a very slow process that occurs below detectable levels until the aggregates coalesce to a visible size.

\section{Peripheral (intramuscular) injection of soluble $\alpha S$ and PFSPs in $\alpha$ S transgenic mice}

To further investigate the hypothesis that $\alpha \mathrm{S}$ pathology can self-template and spread from the periphery into the CNS via peripheral nerves, PFSPs were injected in the hind leg muscle (either biceps femoris or gastrocnemius) in $\mathrm{M} 83^{+/+}, \mathrm{M} 83^{+/-}$or $\mathrm{M} 20^{+/-} \alpha \mathrm{S}$ mice [161]. In addition, an advantage of this simple non-CNS invasive procedure is that it does not alter brain homeostasis as does brain stereotactic surgeries. The intramuscular (IM) injection of PFSPs in $\mathrm{M}_{83} 3^{+/+}$and $\mathrm{M} 83^{+/-} \alpha \mathrm{S}$ mice resulted in the rapid and synchronized development of hind limb motor weakness associated with robust induction of CNS $\alpha \mathrm{S}$ pathology, predominantly in the spinal cord, brainstem and midbrain areas [161]. This pathological changes occurred at $\sim 2$ to 3 months following IM injection in $\mathrm{M}_{8} 3^{+/+} \alpha \mathrm{S}$ mice and 
$\sim 3$ to 4 months for $\mathrm{M} 83^{+/-} \alpha \mathrm{S}$ mice. IM injections of PFSPs into M $20^{+-} \alpha \mathrm{S}$ mice did not result in any motor phenotype, but induced a progressive accumulation of CNS $\alpha \mathrm{S}$ inclusion pathology moving up the spinal cord detectable at 4 months post-injection and increasing thereafter up to 12 months, the last time point assessed [161]. To provide evidence that the induced CNS $\alpha \mathrm{S}$ inclusion pathology following IM injection of PFSPs was due to retrograde transport through the sciatic nerve (the major nerve that innervates lower leg muscles), complete transection of the left sciatic nerve was performed 3 days prior to the IM injection of PFSPs in the left gastrocnemius muscle of $\mathrm{M} 83^{+/-}$ $\alpha S$ mice [161]. The sciatic nerve transection significantly delayed and in some mice perhaps completely prevented the induction of CNS $\alpha \mathrm{S}$ inclusion pathology [161]. However, a subset of these mice still developed motor impairment with CNS $\alpha \mathrm{S}$ pathology identical to mice without nerve transection. These findings demonstrated that retrograde transport of PFSPs is partially responsible for the induction of CNS $\alpha \mathrm{S}$ pathology in this model, but either other routes including perhaps other minor nerves or transport through blood may also be involved in inducing distant CNS $\alpha \mathrm{S}$ pathology in predefined fashion. However, IM injection of soluble non-amyloidogenic $\Delta 71-82 \alpha \mathrm{S}$ was also able to induce $\mathrm{CNS} \alpha \mathrm{S}$ inclusion pathology, albeit less efficiently than PFSPs, indicating that peripheral inoculation of soluble $\alpha \mathrm{S}$ must also be able to trigger the formation of CNS $\alpha \mathrm{S}$ pathology by a mechanism that most likely does not involve protein conformational templating [161].

\section{Evidence for $\alpha S$ pathogenic transmission and $\alpha S$ conformational templating in WT mice}

Recasens and colleagues demonstrated that the nigral injection of LB-enriched extracts from the SN of postmortem PD brains can result in the progressive demise of nigrostriatal dopaminergic neurons in mice associated with increased pSer129 staining and diffuse $\alpha \mathrm{S}$ aggregates, but clearly defined LB-type inclusions were not observed [152]. In addition, increased levels of pSer129 staining were observed in distal but connected brain regions such as the striatum and motor cortex. The direct involvement of $\alpha S$ inducing these pathological changes was demonstrated in parallel studies with brain fractions lacking $\alpha \mathrm{S}$ or injections in $\alpha \mathrm{S}$ null mice. The neurotoxic effects of these LBcontaining extracts were additionally confirmed in nigral or striatal injection of monkey brain [152].

Cerebral injection of PFSPs can result in the formation of neuronal anti-pSer129 $\alpha$ S-reactive inclusions in WT mice $[124,130,162,173]$, but the extent that this apparent pSer129 $\alpha \mathrm{S}$ pathology is due to aggregated, amyloidogenic $\alpha \mathrm{S}$ has not been unequivocally established due to the over reliance on anti-pSer129 antibody staining. For example, the cerebral injection of exogenous $\alpha \mathrm{S}$ can result in a rapid, robust but transient increase in pSer129/81A staining that is due to increased phosphorylated NFL staining [162]. Similar to the short half-life of PFSPs in neonatal brains, Masuda-Suzukake and colleagues reported that injected PFSPs in adult brains demonstrated a half-life of less than 7 days [130], but about 30 days therefore pSer129-reactive inclusions started to appear [130]. Cerebral injections of brain extracts from patients with $\alpha \mathrm{S}$ inclusions were also able to induce pSer129-reactive inclusions in the brain of WT mice. Interestingly, the time lapse between the detection of the PFSPs and the appearance of detectable pSer129-reactive inclusions suggests that some populations of PFSPs remain below detectable levels or that the PFSPs were able to initiate the seeding or slow formation of $\alpha \mathrm{S}$ inclusions before being degraded.

Additional studies also suggest that brain $\alpha \mathrm{S}$ inclusion pathology induced by the cerebral injections of PFSPs in WT mice appear to spread from the injection site [124, 129, 173]. Again the majority of these data were mainly based on $\alpha \mathrm{S}$ pSer129 immunostaining, but in some studies at least a subset of inclusions, but without a thorough parallel mapping of pathology distribution, were confirmed with an antibody to non-phosphorylated $\alpha \mathrm{S}$ [124, 173]. This apparent spread of $\alpha \mathrm{S}$ inclusion pathology has been attributed to amyloid-like conformational templating. However, it is important to emphasize that a gradient of injected $\alpha \mathrm{S}$ away from the injection site, possibly along normal anatomical connections, could lead to the progressive appearance of $\alpha \mathrm{S}$ pathology. In this scenario, there could be progressive "seeding" but no true spread except for distribution of the exogenous seeds. Consistent with this possibility, Rey and colleagues have shown that the injection of exogenous monomeric or aggregated $\alpha \mathrm{S}$ in mouse olfactory bulb can result in the transport to neurons of neuroanatomically connected brain regions, and here also the injected proteins had a short half-life (less than $72 \mathrm{~h}$ ), but no induction of $\alpha \mathrm{S}$ pathology was observed in these short-term studies [153]. Importantly, these experimental mouse studies also have not definitely addressed the direction (i.e., anterograde versus retrograde) of exogenous $\alpha \mathrm{S}$ transport.

Not every PFSPs cerebral injection studies using mice expressing natural levels of $\alpha \mathrm{S}$ have supported the notion that this challenge could lead to the induction and spread of authentic $\alpha \mathrm{S}$ inclusion pathology. As such, the cerebral injection of PFSPs, which could robustly seed $\alpha \mathrm{S}$ inclusion pathology in cultured cells, only induced a very limited amount of $\alpha \mathrm{S}$ inclusion pathology in mice that overexpressed tau protein but with normal levels of endogenous $\alpha S$ [75]. Moreover, in another study, the presence of $\alpha S$ inclusion pathology in WT mice following cerebral PFSP injection was limited to the injection site and it actually diminishes over time rather than progressively spreading 
[162], suggestive of important biological barriers that can thwart the spread of $\alpha \mathrm{S}$ inclusion pathology.

The peripheral IM injections of PFSPs in WT mice did not result in the induction of CNS $\alpha \mathrm{S}$ pathology [161]. The lack of induction of CNS $\alpha \mathrm{S}$ pathology following robust peripheral inoculation with PFSPs was also shown by Masuda-Suzukake and colleagues where the intranasal administration of $80 \mu \mathrm{g}(4 \times 20 \mu \mathrm{g})$ of PFSPs did not yield CNS pathology even almost 2 years after the exposure [130]. This paucity of CNS $\alpha \mathrm{S}$ induction pathology in WT mice following the peripheral exposure to PFSPs is consistent with the normally low level of expression of endogenous $\alpha S$ in the peripheral nerve and the spinal cord in WT mice $[63,161]$. This intrinsic low expression of $\alpha S$ in the PNS constitutes another nature barrier to transmission of $\alpha \mathrm{S}$ inclusion pathology.

\section{Rat studies of induction of $\alpha$ S pathology using exogenous} $\alpha S$

Paumier and colleges recently showed that the unilateral striatal injection of recombinant mouse PFSPs [146] in rats induces the formation pSer129/81A-reactive neuronal aggregates that over time accumulate in areas that innervate the striatum such as the SN pars compacta, amygdala, frontal cortex and insular cortex. As noted above the pSer129/81A antibody can strongly cross-react with other phospho-proteins including NFL. The formation of protein inclusions was documented with other markers such as Nucleoporin 62/sequestosome-1 (p62/ SQSTM1), but localization with $\alpha \mathrm{S}$ antibodies was weak [146]. Interestingly other brain regions, such as the locus coeruleus (LC) and the raphe, innervating to the striatum did not develop pSer129/81A-positive accumulations, suggesting selective neuronal vulnerability in this process. Despite the findings that pSer129/81A-positive accumulations were only observed in the ipsilateral SN pars compacta, similar bilateral demise of nigral dopaminergic neurons was observed [146] indicating that the injection of mouse PFSP must induce additional pathogenic mechanisms in addition to protein conformational templating since $\alpha \mathrm{S}$ inclusion formation was not required to induce the demise of these neurons and the induced toxic mechanism did not follow neuroanatomical pathways. Further supporting this notion is the findings that a similar unilateral striatal injection of soluble, non-aggregated mouse $\alpha \mathrm{S}$ can also induce similar pSer129/81A accumulations and the demise of nigral dopaminergic neurons, although the formation of protein aggregates occurred at a slower rate [146]. Interestingly, the number of pSer129/81A-reactive aggregates in the SN pars compacta following the striatal injection of PFSPs decreased with time, despite nigral dopaminergic demise being similar, indicating that the formation of these aggregates can be reversible [146].

Peelaerts and colleagues recently showed that the direct rat nigral injections of PFSPs preparations with different structural properties defined as "fibrils" or "ribbons" were taken up by dopaminergic neurons and induced increased pSer129 immunoreactivity, but without a concomitant demise of nigral dopaminergic cells [147] demonstrating that these $\alpha \mathrm{S}$ species were not intrinsically toxic. However, similar nigral injections of PFSPs in rats overexpressing human A53T $\alpha \mathrm{S}$ in dopaminergic nigral neurons using rAAV (see below) could exacerbate the neurotoxicity driven by A53T $\alpha \mathrm{S}$ overexpression [147]. These studies also reported that some exogenous human PFSPs could be able to cross the blood-brain barrier and enter the CNS after tail vein injections, but this was accomplished using a substantial amount of PFSPs ( $80 \mu \mathrm{g}$ total-8 injections of $10 \mu \mathrm{g}$ each) [147].

\section{Pathological sequelae of local overexpression of $\alpha \mathrm{S}$ through viral delivery}

rAAV was used to mediate the expression of human $\alpha \mathrm{S}$ in rat vagus nerve and specifically track the temporal and spatial distribution following $\alpha \mathrm{S}$ expression [176]. As expected, human $\alpha \mathrm{S}$ was initially detected in the medulla oblongata since the vagus nerve is comprised of axons that originate and terminate in the medulla oblongata and upper cervical spinal cord. However, at later time points human $\alpha \mathrm{S}$ could also be detected in a limited number of more rostral neuronal projections in the pons, midbrain, and forebrain. Interestingly, no exogenous human $\alpha \mathrm{S}$ was found in cell bodies and it was not present in the SN pars compacta. These findings were interpreted as an evidence for transneuronal caudal to rostral spread of $\alpha \mathrm{S}$.

Several studied have used viral vectors (rAAV or lentivirus) to express $\alpha \mathrm{S}$ in adult rats' or monkeys' nigral dopaminergic neurons to assess the pathological consequences. Expression of human WT, A30P or A53T $\alpha \mathrm{S}$ in rat or monkey nigral dopaminergic neurons using rAAV that stably expresses the transgene ( $>6$ months) resulted in substantial and specific demise of these neurons (30-80\% loss), concurrent with the formation of cellular $\alpha \mathrm{S}$ cytoplasmic inclusions and dystrophic neurites [99-101]. Similar results were observed when using a lentiviral-based vector system to express $\alpha \mathrm{S}$ proteins in rat nigral dopaminergic neurons [122]. However, it is important to note that in these studies $\alpha \mathrm{S}$ pathology was exclusively observed in the neuronal populations transduced to express human $\alpha \mathrm{S}$ and that no evidence for transmission of $\alpha \mathrm{S}$ pathology to other neuronal population was observed despite that they express endogenous $\alpha \mathrm{S}$. Nevertheless, since spread of $\alpha \mathrm{S}$ pathology was not a major focus of these studies, such a 
Fig. 3 Summary of biological mechanisms that may synergistically promote neurodegeneration with concomitant formation of $\alpha \mathrm{S}$ inclusion formation

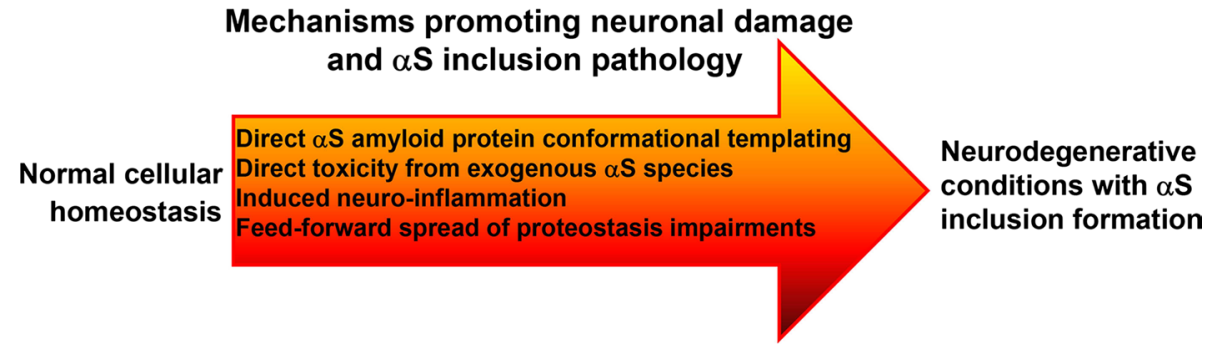

process could have been unnoticed. These findings further support the notion that there exist potent biological barriers to prevent the inter-neuronal transmission of $\alpha \mathrm{S}$ inclusion pathology. It is also possible that the $\alpha \mathrm{S}$ aggregates generated in these expression systems are not permissive to transmission.

\section{Important issues and mechanisms to consider when interpreting experimental induction of $\alpha \mathrm{S}$ inclusion pathology in rodents: potential pitfalls of experiments}

Potential pitfalls of current experimental paradigms are summarized as follows:

\section{Excessive amount of PFSPS}

The amounts of PFSPs that were used experimentally to induce $\alpha \mathrm{S}$ inclusion pathology in mice and rat are much larger that would normally be locally encountered even if many cells died simultaneously releasing $\alpha \mathrm{S}$ aggregates. Thus, it is possible that in the experimental studies using PFSPs the natural barriers to induction and spread of $\alpha \mathrm{S}$ induction pathology were artificially overwhelmed beyond concentrations that would normally occur. On the other hand, these studies are modeling human neurodegenerative diseases with changes progressively occurring throughout many years or decades and in aging brains that typically can have multiple proteinopathies likely reducing the normal abilities to cope with protein misfolding.

\section{Questionable artificial enhancement of susceptibility}

$\alpha \mathrm{S}$ transgenic mice are much more susceptible to the induction and spread of $\alpha \mathrm{S}$ protein inclusion pathology compared to WT mice [160-162]. Therefore, under normal expression levels induced $\alpha \mathrm{S}$ inclusion pathology may not be very robust, suggesting that normal biological activities can cope with even a bolus insult of aggregated protein. The vulnerability of $\alpha \mathrm{S}$ transgenic mice could be due to both the overexpression and ectopic, non-neuronal expression of transgenic $\alpha \mathrm{S}$. $\alpha \mathrm{S}$ is naturally a highly expressed brain protein, so it is not surprising that transgenic overexpression renders these mice highly primed to the induction of protein aggregation.

\section{Bystander contributions other than molecular conformations}

Although studies using cerebral injection of PFSPs or brain extracts are suggestive of induction and spread of $\alpha \mathrm{S}$ induction pathology by protein conformational templating, there are many important issues to consider that make it likely the experimental procedures potentiate this process and that several other mechanisms are involved (Fig. 3). The brain surgical stereotactic procedures used to inject exogenous $\alpha \mathrm{S}$ cause both tissue and cellular damage that can greatly promote cellular uptake. Furthermore, it is difficult to completely rule out that some of the observed spread of $\alpha S$ pathology is not simply due to the dispersion of PFSPs in part due to the disruption of cerebral tissue due to needle injections. Once the formation of intracellular $\alpha \mathrm{S}$ inclusions have been initiated, these aggregates should actually serve as "magnets" to existing cellular amyloidogenic forms of $\alpha S$ thus hampering the spread of $\alpha S$ inclusion pathology at least until the cell demise, but in the experimental cerebral injection models robust cell death associated with the spread of $\alpha \mathrm{S}$ inclusion pathology has not been reported. In addition, the findings that challenges with soluble $\alpha \mathrm{S}$ including non-amyloidogenic $\Delta 71-82 \alpha \mathrm{S}$ can also induce $\alpha \mathrm{S}$ inclusion pathology in $\alpha \mathrm{S}$ transgenic mice and WT rats [146, 159-161] strongly suggest that other mechanisms are involved. If fact, it is possible that the cerebral injection of brain lysates or PFSPs have predominantly demonstrated the initiation of $\alpha \mathrm{S}$ pathology due to biological insults.

\section{Proteostatic perturbations}

The cerebral injection of PFSPs or brain lysates from terminally motor impaired animals could lead to proteostatic perturbations, especially in primed $\alpha \mathrm{S}$ transgenic mice thus initiating a progressive cycles of $\alpha \mathrm{S}$ accumulation and aggregation. Mechanistically, the two major cytoplasmic protein degradation machineries, proteasome and lysosomal-autophagy, can be inhibited by various forms 
of aggregated $\alpha \mathrm{S}[38,49,50,65,127,178,192]$ that can contribute to the progressive spread of $\alpha \mathrm{S}$ pathology. This notion would be consistent with a more global impairment in proteostasis that was noted in one study [160].

\section{Glial involvement}

The robust activation of gliosis that coincides with the formation of $\alpha \mathrm{S}$ inclusion pathology in the $\alpha \mathrm{S}$ transgenic models challenged with PFSPs is also suggestive that this process participates in the spread of pathology, either by the aberrant formation of $\alpha \mathrm{S}$ in glial cells (Fig. 3) [125, 160] or by inducing inflammatory cellular damage $[25,70,115]$. The original injected PFSPs and additional soluble and aggregated $\alpha \mathrm{S}$ released from damaged cells can be potent activators of inflammation [25, 34, 97, 115, 156, 195]. In addition, it should not be overlooked that various forms of exogenous $\alpha \mathrm{S}$ could directly lead to cellular toxicity [40, $51,94,120]$, which may also lead to spread of pathology by a positive-feedback process of cellular damage, inclusion formation, and release of $\alpha \mathrm{S}$ aggregates.

\section{Structural template (neuroanatomical considerations)}

\section{Distally accentuated deficit of nigrostriatal and cardiac sympathetic systems: an intraneuronal gradient}

In human brains, loss of nigral dopaminergic neurons with LB is the hallmark for PD [73] and explains the deficiency of dopamine in nigrostriatal system. The rate of LB formation is proportional to surviving nigral neurons and precedes their loss [74], although the real role of LB (toxic or protective) in PD remains to be clarified [113]. The number of surviving nigral neurons at the onset of motor deficits of PD is estimated to be $70 \%$ of age-matched control [32]. This estimation is based on an extrapolation from different autopsy series. Deficiency of dopamine at their axon terminals in caudate/putamen is more profound (30 \% of agematched control) [32] than the loss of nigral neurons [85], indicating distally accentuated gradient of degeneration, also confirmed by PET studies in PD patients at the onset of motor deficits. It remains to be clarified what kind of structural changes are responsible for such distally accentuated deficits in the human brains. However, tracing neurite lesion in the human central nervous system is so complex that the identity (dendrite or axons) and the polarity of neurites harboring pathological deposits are not always evident.

Examination of epicardial nerve fascicles provides a unique opportunity to evaluate how cardiac sympathetic nerves, frequently affected in PD in its early stage, are involved in PD. Histological comparison of cardiac sympathetic nerve at different stages from presymptomatic PD (cases with LBs without clinical manifestations of PD, incidental LB disease: ILBD) to full-blown PD demonstrated that $\alpha \mathrm{S}$ deposition commences within distal axons at the presymptomatic phase and spreads towards the neuronal perikarya followed by axonal demise [143] (Suppl. Figure 3). The simple morphology and connection of the cardiac sympathetic nerve clarified the anatomopathological temporal substrate with distally accentuated $\alpha \mathrm{S}$ deposition followed by axonal depletion. Subsequent loss of noradrenalin terminals is detectable as decreased myocardial uptake of radio-labeled meta-iodobenzylguanidine (MIBG) as a tracer relative to its mediastinal uptake as the reference (H/M ratio). One of the advantages of myocardial MIBG is its quantitative nature. Such a quantitative feature is hardly detected with other indices of autonomic functions because autonomic functions are usually represented as a balance between sympathetic and parasympathetic systems. As a consequence, progressive decline of $\mathrm{H} / \mathrm{M}$ ratio in PD patients may suggest a progressive depletion of sympathetic axons in the cardiac tissue [142]. Indeed, direct comparison between remnant axons in epicardial nerve fascicles and myocardial uptake of MIBG (H/M ratio) performed premortem in the same patients confirmed their quantitative correlation in a cohort with different stages from ILBD to dementia with LB (DLB) [172].

\section{Distally accentuated vulnerability in hyper-branched axons as a structural basis to template distal-dominant neurodegeneration}

It is proposed that LBs are preferentially formed in projection neurons with long, thin unmyelinated axons [20]. It is expected that energy/metabolic burdens and oxidative stress $[80,169]$ can be significantly accentuated in these types of neurons [149]. In addition, nigrostriatal axons are characterized by excessive branching, which exponentially enhances these burdens by increasing the number of synapse at the each axon terminal (Fig. 4). Indeed, the number of striatal synapses from a single dopaminergic neuron is estimated to be $102,165-245,103$ in rat [131], while it is ten times more abundant to $1,000,000$ $2,400,000$ in human [18], which provides a basis for the distally accentuated vulnerability of nigrostriatal axons. Because some of the genes harboring mutation related to familial levodopa-responsive parkinsonism are related to mitochondria and their functions [128, 136], subsequent energy failure through mitochondrial dysfunction may predispose the nigrostriatal system to degenerate especially in axon terminals regardless of Lewy pathology [128]. Moreover, numerous axon terminals may serve as a portal of entry of external toxins such as 


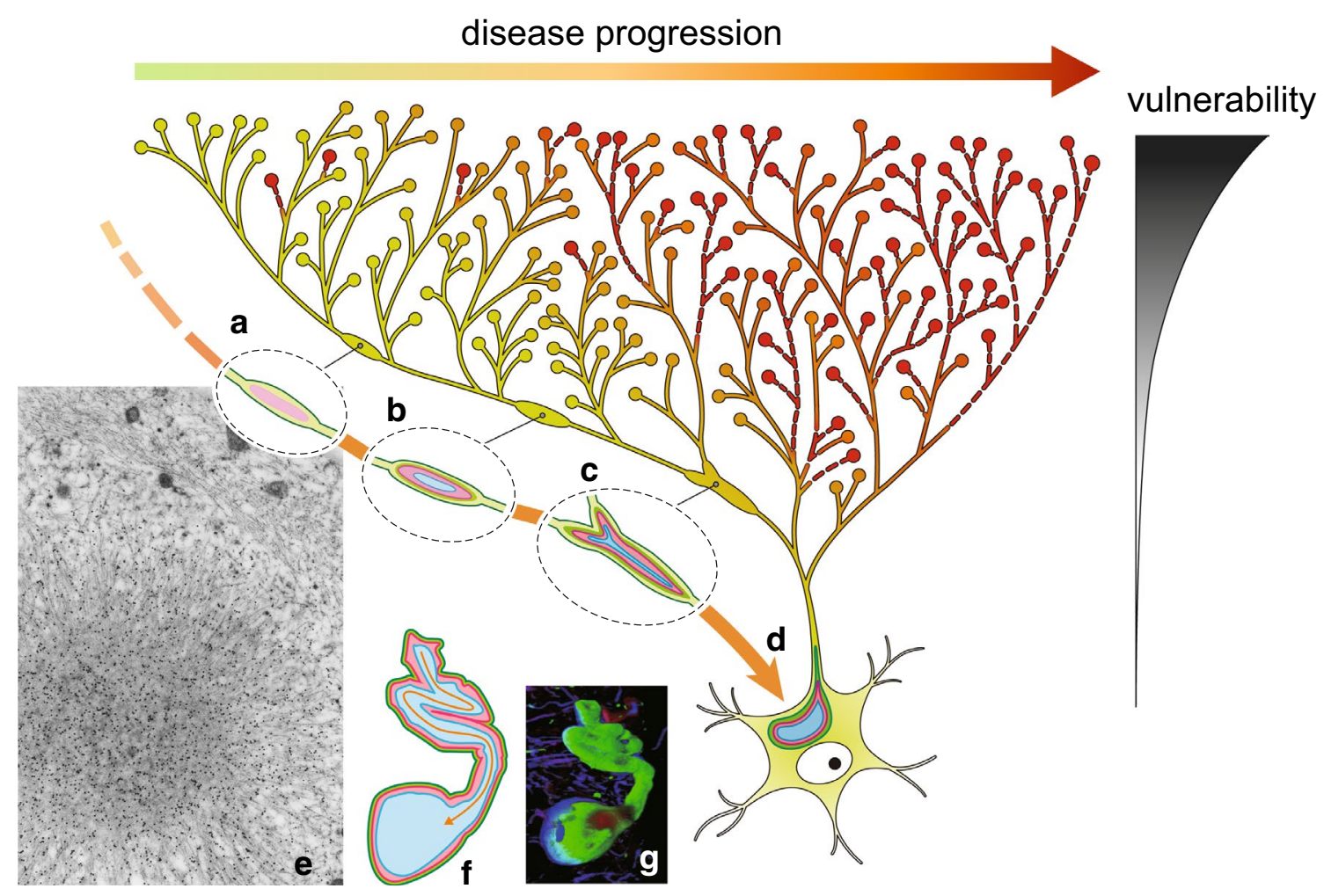

Fig. 4 Intraneuronal gradient/progression of Lewy pathology from axon terminals to neuronal soma. Nigrostriatal dopaminergic projections are characterized by long and thin axons with hyperbranching. This structural characteristic enhances distal vulnerability by increasing the length of axons and the number of synaptic terminals, which exponentially enhance the energy burden especially at their distal ends. Normal axon terminals/distal axons (green) are gradually filled with $\alpha \mathrm{S}$ (red) along disease progression as indicated by the horizontal arrow to the right. Although it remains to be clarified how such energy expenditure is related to $\alpha \mathrm{S}$ deposition, such hyperbranching state enhances the probability of distal axons and terminals to be involved and induces a vicious cycle through enhancing further the progressive compromise in the metabolic support by the decreased number of axons. $\alpha \mathrm{S}$ deposition in swollen axons is one of the earliest

1-methyl-4-phenyl-1,2,3,6-tetrahydropyridine (MPTP) or rotenone to template PD-like symptoms irrespective of Lewy pathology [14]. All of these are compatible with "a mitocentric view of PD" [76, 80].

\section{Hyperbranching axons as a structural template for Lewy-prone systems and their clinical manifestations}

Lewy pathology is not restricted to the nigrostriatal system but also occurs in a variety of systems with different neurotransmitters such as noradrenergic (sympathetic, LC), cholinergic (parasympathetic, nucleus basalis of Meynert), and serotoninergic (raphe nuclei, raphe) [20, 139] (Fig. 5). Although possible toxicity of dopamine and its metabolites may explain relative accentuation of nigral degeneration, axonal changes (pale neurite $a$ ). Because deposition of $\alpha \mathrm{S}$ is frequent at branching points (Lewy neurites: LNs: $b, c$ ), hyperbranching axons as in the nigrostriatal system may facilitate $\alpha \mathrm{S}$ deposition. They spread toward neuronal perikarya, where mature LBs $(d)$ are formed. The outermost layer of LBs is composed of neurofilaments (green $d$ ), while the innermost layer is composed of ubiquitin (blue $d$ ) with $\alpha \mathrm{S}$ in between (red $d$ ). This three-layered structure, confirmed also by immunoelectron microscopy $(e)$ is shared between LNs $(c)$ and LBs $(d)$. Furthermore, each layer is continuous when a LN is in continuity with a LB $(f)$, suggesting that LNs evolve into LBs or Lewy pathology spreads from axon to neuronal soma. (orange arrow); $f, g$ modified from Kanazawa et al. [93]; $e$ courtesy, Dr. Masakuni Arima (Director, Komoro Kogen Hospital)

the modality of neurotransmitter is not the major determinant for LB formation. Instead, a unique structural characteristic common to these Lewy-prone systems is hyperbranching of long projection axons which innervate to wide areas in the brain as shown in Fig. 5 [170]. It is likely that this structural template similarly (1) increase the chance to develop $\alpha \mathrm{S}$ deposition at these axon terminals, which facilitates $\alpha \mathrm{S}$ deposition and (2) this further exacerbates metabolic burden and oxidative stress at axon terminals in these Lewy-prone systems. Centripetal (retrograde) progression of axonal lesion as seen in nigrostriatal and cardiac sympathetic systems may be shared as a rule by these Lewy-prone systems with long projection axons. Of course, this does not necessarily exclude the possibility of intraneuronal spread in the reverse direction, from soma to axon terminals. Indeed, it remains to be clarified 
Fig. 5 Lewy-prone systems and neurotransmitters. Although the neurotransmitters are different between associated systems, these Lewy-prone systems are characterized by widespread innervation to cerebral cortex, basal ganglia, hippocampus through hyperbranching axons. Such structural template facilitates $\alpha \mathrm{S}$ deposition. Such excessive branching of axons is also related to their normal functions or dysfunctions uniformly characterized by non-focal or generalized influences without somatotopy. $n b M$ nucleus basalis of Meynert, $d m X$ dorsal motor nucleus of vagus, $S N$ substantia nigra, Raphe raphe nucleus, $L C$ locus ceruleus, ggl. ganglia; modified from Nolte and Angevine [139] with permission

\section{Transmitters in Lewy-prone systems projections Related functions or clinical manifestations}

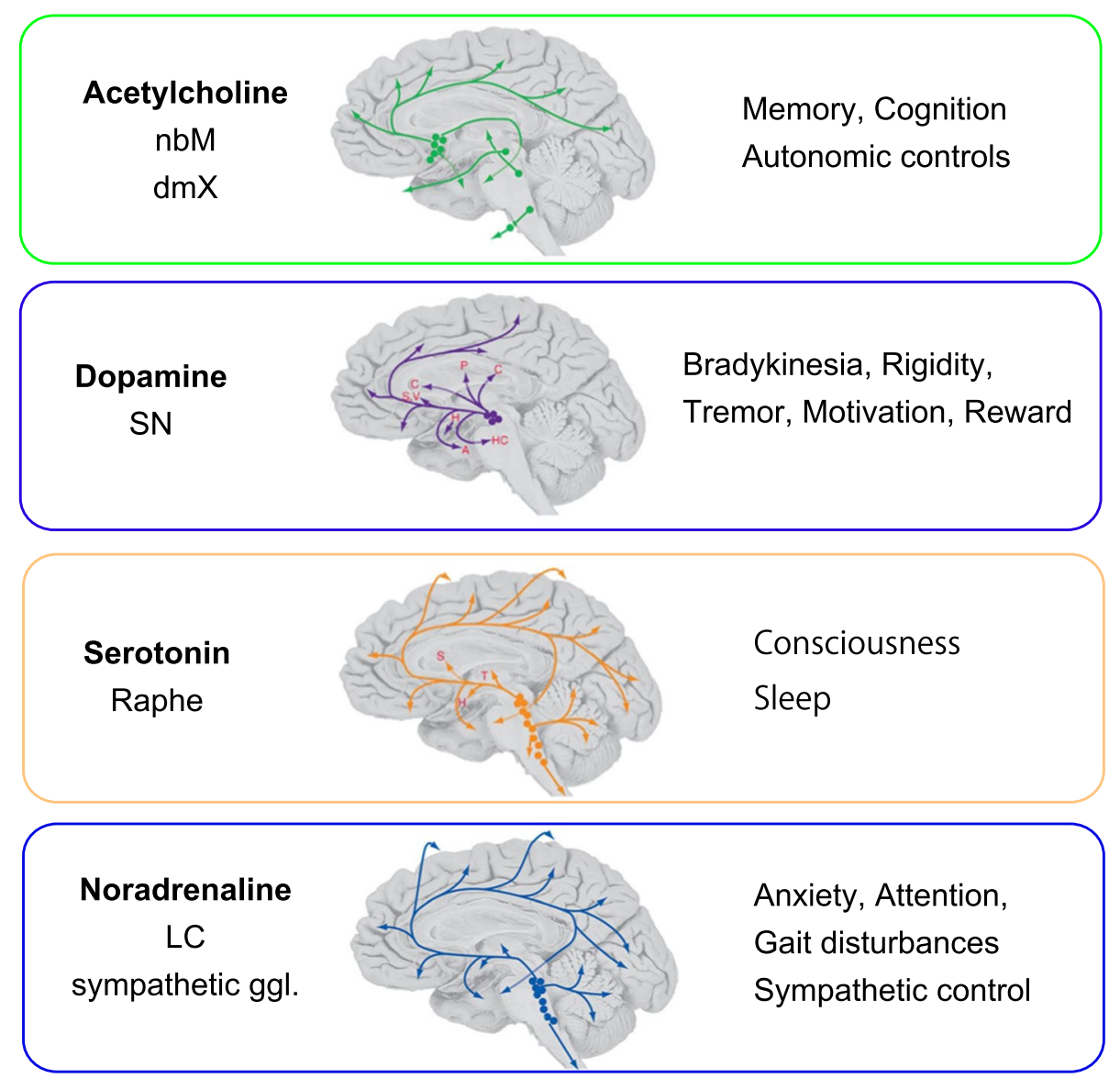

whether similar progression along axon is shared in olfactory-amygdala axis [174] or in the striatum, where smaller neurons with shorter axons are intermingled.

From a clinical point of view, such a hyper-branched status of long axon is correlated with their physiological functions and their clinical manifestations without somatotopical presentation. For example, the dopamine deficiency of the nigrostriatal system is related to Parkinsonism and cognition. Cholinergic projections from nucleus basalis of Meynert are related to memory and cognition. Those from parasympathetic nuclei (dorsal motor nucleus of vagus) are related to autonomic regulation. Serotonergic projections from raphe nuclei are related to anxiety, arousal, sleep or nociception. Noradrenergic projections from LC are related to mood, attention and gait. Thalamocortical projection may be related to fluctuation of dementia or hallucination [82]. Such "holistic organization based on large interconnectivity [46]" of Lewy-prone systems is in sharp contrast with the highly organized somatotopy in the primary motor efferent and the primary sensory afferent systems. Such organization is suitable to modulate final motor pathways or primary sensory pathways by exerting more generalized (non-localizationist) influence mainly in an indirect fashion. Consequently, clinical manifestations related to these Lewy-prone systems are vague and generalized such that localizationist recognition of their clinical manifestations is practically difficult.

\section{Axonal $\alpha S$ spreads toward LB in neuronal soma as in cardiac sympathetic nerve}

Although it is established that $\alpha \mathrm{S}$-positive axons appear prior to the formation of LBs [23] (Suppl. Figure 3), it remains to be clarified how Lewy neurites (LNs, mainly in axon) and LBs are related. Three-dimensional analysis of triple-labeled LBs and LNs demonstrated a three-layered structure with neurofilament at the outermost layer, ubiquitin in the core and $\alpha \mathrm{S}$ in between [93]. Because each of these three layers is continuous even at the branching point (Fig. 4c) and the junction between LB and LN (Fig. 4d), it is probable that some of LNs in axon may expand to form LB in soma, suggesting again that Lewy pathology extends from neurite to soma to form LB. Furthermore, LNs frequently occur at the branching point of axons (Fig. 4c), it is likely that some local environment related to branching, such as trouble in transport, 
may predispose $\alpha \mathrm{S}$ deposition at each branching point [92]. Although the exact mechanisms for $\alpha \mathrm{S}$ deposition at distal axon/synapse [10, 57] and for the preferential deposition at branching points still remain to be clarified, all of these findings are compatible with the observation that spread of axonal $\alpha \mathrm{S}$ deposition is followed by axonal depletion to yield the socalled distal-dominant degeneration. Because hyperbranching of axons may predispose not only axon degeneration but is associated also with $\alpha \mathrm{S}$ deposition, it is plausible that such structural characteristics may feature selective vulnerability of all Lewy-prone systems including peripheral sympathetic systems as their "structural template". Distal axons could be dysfunctional or depleted early in the disease course even when their respective neuronal cell bodies remain relatively intact (intraneuronal gradient). Awareness of such early neurite pathology before neuronal death $[32,119]$ will require the revision of the cell death-oriented paradigm of neurodegeneration to "neurite pathology" or "nexopathy", so that earlier and more relevant to clinical manifestations are detected for early therapeutic intervention $[27,183]$.

\section{Early autonomic involvement in PD}

Autonomic nervous system outside the CNS serve as direct effectors (vasomotor, sudomotor, pilomotor, visceromotor) or includes primary sensory (viscerosensory) components. They are also characterized by unmyelinated hyperbranching axons and therefore frequently harbor $\alpha \mathrm{S}$ deposits. Because cardiac sympathetic nerves could be affected even in asymptomatic patients with incidental LBs in the CNS [143] and there are some cases with $\alpha \mathrm{S}$ deposits exclusively in cardiac sympathetic axons without LB in the CNS [133], it is plausible that cardiac sympathetic nerves are one of the initial sites of Lewy pathology involvement. Some peripheral autonomic axons and ganglia are accessible through skin [47] or gastrointestinal biopsies, which can be used to try to predict the presence of CNS LBs [83]. More extensive histological comparison of CNS, spinal and peripheral autonomic system for $\alpha S$ in an autopsy cohort of 98 patients without clinical manifestations of PD demonstrated frequent involvement of spinal cord and peripheral autonomic nerves in parallel with olfactory bulb and $\mathrm{dmX}$ [15]. To address how these autonomic involvements by $\alpha \mathrm{S}$ is related to PD, initially asymptomatic patients harboring chance identified $\alpha \mathrm{S}$ deposits in surgical specimens of abdominopelvic organs were followed up for 30 months. Because UPDRD-II scores of these patients were higher and their myocardial uptake of MIBG (H/M ratio) was lower than in $\alpha \mathrm{S}$-negative controls, it is likely that such $\alpha \mathrm{S}$ deposition in neurons of abdominopelvic organs represents one of the earliest stages of PD [135] or pure autonomic failure (PAF) [77]. Unexpected spreads of $\alpha \mathrm{S}$ deposits including autonomic systems are not uncommon [7].

\section{Possible discrepancies between $\alpha \mathrm{S}$ deposition, neuroaxonal depletion and clinical manifestations}

Since initial axonal accumulation of $\alpha \mathrm{S}$ can be followed by loss of axons, the absence of $\alpha \mathrm{S}$ deposits could represent either the absence of Lewy pathology or axonal depletion after formation of Lewy pathology or by other causes such as ischemia. Thus, parallel evaluation of neuroaxonal components is necessary [4, 143]. Depletion of sympathetic axons in the absence of $\alpha \mathrm{S}$ deposits can suggest the presence of Lewy pathology elsewhere, unless otherwise explained by ischemia, for example. However, the absence of $\alpha \mathrm{S}$ deposits may indicate either the total absence of Lewy pathology or loss of neuron after formation of Lewy pathology [74]. Therefore, $\alpha \mathrm{S}$ IHC not assisted by evaluation of neuroaxonal components could be misleading. Additional attention should be paid on possible influences of staining procedures and anti- $\alpha \mathrm{S}$ antibodies, which may greatly alter $\alpha \mathrm{S}$ immunoreactivity [2, 105, 148, 185]. Anyway, abundant $\alpha \mathrm{S}$ inclusion pathology in $\mathrm{dmX}$ may not necessarily be correlated with more profound neuronal depletion, while evident neuronal loss in the $\mathrm{SN}$ is not necessarily correlated with abundant $\alpha \mathrm{S}$ deposits, which should be taken into account when considering regional gradient or lesion spread. Since distal axon and synapse are preferentially affected in LB disease before involvement of neuronal soma, it is possible that apparent preservation of neuronal soma does not assure the functional integrity. Therefore, discrepancies between $\alpha \mathrm{S}$ deposition, neuroaxonal depletion and clinical manifestations could be trivial and troublesome, which should be carefully correlated for sound interpretation. It remains to be clarified whether such discrepancies may be further enhanced or complemented by possible participation of $\alpha \mathrm{S}$ oligomers, now selectively detectable with proximity ligation assay [155] or synaptic $\alpha \mathrm{S}$ detectable with PET blot [106] in human brain. Finally, clinicopathological interpretations may be hampered by coexisting lesions other than $\alpha \mathrm{S}[86,104]$.

In summary, Lewy-prone systems are structurally characterized by long hyperbranching axons that template distal-dominant degeneration with $\alpha \mathrm{S}$ deposits. This degenerative process predominantly starts at distal axons and spreads in retrograde direction towards neuronal soma. This structural feature with barely somatotopic feature is also related to clinical presentations of PD/DLB. How these building blocks are organized into an order in this disorder is discussed below.

\section{Possible mechanism for regional gradient $(\mathrm{dmX}>\mathrm{LC}>\mathrm{SN})$ based on single hit hypothesis}

As initially noted by Lewy, LBs in the $\mathrm{dmX}$ are usually more abundant than those in SN or LC in PD patients. 
This regional gradient $(\mathrm{dmX}>\mathrm{LC}>\mathrm{SN})$ was systematically demonstrated by Del Tredici and Braak [20, 45] based on a series of PD cases with LBs in $\mathrm{dmX}$. Because their careful observations were based on serial thick sections to encompass the entire target nuclei, their irrefutable data are much more reliable and convincing than chance observation on routine single section used in other studies. Furthermore, this apparent gradient in regional hierarchy is consistent with a hypothesis that $\alpha \mathrm{S}$ deposition is always initiated at $\mathrm{dmX}$ and subsequently occurs in LC and finally in SN. Such translation of this stereotyped regional hierarchy into a predefined chronological unidirectional sequence provided a basis to construct a staging framework of PD based on $\alpha \mathrm{S}$ deposition. As a more mechanistic interpretation, this regional gradient is interpreted as a possible spread of $\alpha \mathrm{S}$ deposition from the $\mathrm{dmX}$ to $\mathrm{LC}$ then $\mathrm{SN}$ along neural circuit, as if propagating transsynaptically. This spatiotemporal axis proposed by this conceptualization greatly improved our understanding of PD by displaying its clinicopathological sequence on a defined timetable.

\section{From single hit to multiple hit hypothesis}

In addition to this putative upward progression of $\alpha \mathrm{S}$ lesion from the lower brainstem to upper brainstem, independent involvement of olfactory-amygdala pathway by $\alpha \mathrm{S}$ has been noted [81]. Although direct dopaminergic projection from SN to olfactory bulb was recently identified in rats [84], these two putative axes have been considered not contiguous inside the human brain. One of the alternative explanations for their co-occurrence is that some infectious agents, like virus, may initiate olfactory involvements through nasal cavity and vagal involvements through alimentary tract in parallel. This explanation with virus-like agent, however, awaits confirmation by identifying possible infectious agents. Nonetheless, the concept of this "dual-hit" hypothesis suggests a possibility that initiation of $\alpha \mathrm{S}$ deposition is not necessarily monofocal and could be induced in multiple independent systems by some factors outside the neuraxis. How these Lewy-prone systems are related or not is one of the major issues in this series as discussed below.

\section{Is the distribution of Lewy pathology sufficiently hierarchal to corroborate a unified hypothesis of unidirectional spread?}

Typical gradient of Lewy pathology $(\mathrm{dmX}>\mathrm{LC}>\mathrm{SN})$, initially proposed by Del Tredici and Braak [20, 45], is observed in some of (but not all) the cases in other series [78]. Data on this gradient in human brain are, however, still highly conflicting and cases with LB pathology not in agreement with this gradient are being accumulated [8,
26, 90, 91, 144]. Moreover, exceptional cases with LBs in cerebral cortices with less involvement in the brainstem have been reported [103, 193], suggesting that initiation at the lower brainstem is not a prerequisite for development of LB pathology. Additional exceptions include (1) LBs only in cardiac sympathetic nerve [133], (2) their selective appearance only in LC [123], (3) their selective appearance in the autonomic system as in PAF [77] and (4) REM sleep behavior disorder (RBD) which is frequently associated with Lewy pathology [17] and could be a prodrome long before the development of overt motor deficits of PD type. Although anatomopathological substrates for RBD remain to be clarified $[16,48]$, it is likely that Lewy pathology different from typical PD which may be related to this peculiar clinical manifestations. Although such focal and isolated LB depositions are not in accordance with the typical gradient $(\mathrm{dmX}>\mathrm{LC}>\mathrm{SN})$, these could be preludes to full-blown PD or DLB. Importantly, parkinsonism is not a necessary feature for these exceptional cases. These focal presentations of LBs could be termed "focal LB disease", suggesting possible independent development of Lewy pathology in different Lewy-prone systems. Because such "non-motor" symptoms are clinically detectable even before the appearance of parkinsonism, how to take these "unpredictable" clinical features, possibly related to Lewy pathology, into account of diagnosis and management is one of the key issues in the clinical field. Nevertheless, the clinical and pathological heterogeneities indicate that the involvement of Lewy-prone systems is not exclusively stereotyped as to corroborate its unidirectional spread.

\section{Possible interneuronal connections between Lewy-prone systems to explain disease evolution}

Even though distribution of LB pathology could be heterogeneous, there are cases with typical gradient of Lewy pathology $(\mathrm{dmX}>\mathrm{LC}>\mathrm{SN})$ as formulated by Braak and Del Tredici. Even though brainstem nuclei are interconnected with each other directly or indirectly [44], it is not yet clarified which anatomical pathways may provide solid infrastructures to facilitate spreads of $\alpha \mathrm{S}$ lesions across the systems from $\mathrm{dmX}, \mathrm{LC}$ to $\mathrm{SN}$ in the human brainstem. It is worth considering how such gradient could be generated. As shown in Fig. 6, each of these systems is mainly equipped with major efferent projections with hyperbranching axons: upward projection from $\mathrm{SN}$; downward projection from dmX; and both up- and downward projections from LC. In each system, $\alpha \mathrm{S}$ lesion spreads retrogradely along these hyperbranching axons from axon terminal to neuron (Fig. 6, large orange arrows). If such intraneuronal progression along these projecting axons is unidirectional in each system $(\mathrm{dmX}, \mathrm{LC}, \mathrm{SN})$, these intraneuronal 


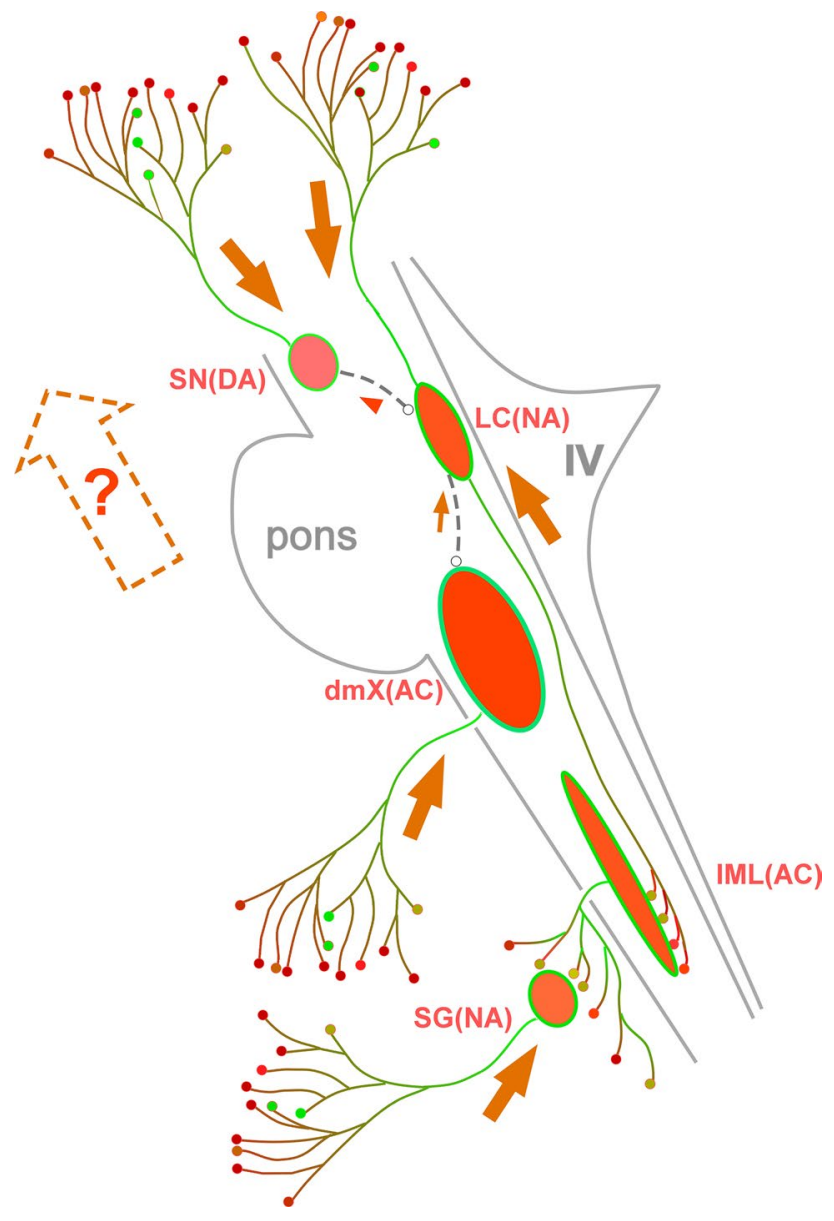

Fig. 6 Intraaxonal progression of Lewy pathology in Lewy-prone systems. $\alpha \mathrm{S}$ pathology is initiated at distal axons and spreads toward neuronal cell bodies in each Lewy-prone system as indicated by orange arrow, respectively. This axonal spread is in parallel with the direction of the so-called the "upward spread" (broken and empty arrow containing "?") up to LC. However, the direction of this axonal spread is "downward" above LC. Additional projections form SN to LC (gray interrupted line) and that from LC to $\mathrm{dmX}$ (gray interrupted line) may be one of the candidate structures that may mediate transneuronal spread from $\mathrm{dmX}$ to LC (small arrow in orange) and that from LC to SN (arrowhead in orange), while these have not yet been documented in human brains with LB disease. $D A$ dopamine, $N A$ noradrenalin, $I V$ forth ventricle, $A C$ acetylcholine, $S G$ sympathetic ganglia, $I M L$ intermediolateral nucleus

spreads are not sufficient to explain the upward progression from $\mathrm{dmX}, \mathrm{LC}$, to $\mathrm{SN}$, which may require additional transsynaptic transmission. If axonal spread of $\alpha \mathrm{S}$ deposit is retrograde and descending as shown in Fig. 6 (descending orange arrows to $\mathrm{SN}$ and $\mathrm{LC}$ ), it is still necessary to explain the ascending $\alpha \mathrm{S}$ pathology by other pathways. Additional projections form SN to LC (Fig. 6, gray interrupted line) and that from LC to $\mathrm{dmX}$ (Fig. 6, gray interrupted line) may be one of the candidate structures that may mediate transneuronal spread from $\mathrm{dmX}$ to LC (small arrow in orange) and that from LC to SN (arrowhead in orange). Even though such downward projections [182] from SN to LC [29] and those from LC to dmX [190] have been reported, it is not yet clarified whether these candidate or other connections are neuroanatomical substrates to facilitate predictable and stereotyped spreads of $\alpha \mathrm{S}$ aggregates between these LB-prone nuclei. Although complete neuroanatomical map for possible networks between these brainstem nuclei is far beyond the scope of this review, more detailed studies to demonstrate contiguous $\alpha \mathrm{S}$ lesion, if any, by tracing along these candidate structures may reinforce the hypothesis of transneuronal spread by way of axon. Otherwise, morphological substrates for stereotyped progression of $\alpha \mathrm{S}$ remain hypothetical in the human brain.

\section{Could direction of intra- and interneuronal spread of $\alpha \mathrm{S}$ be reversible?}

Even if the connections discussed above would be available, this explanation may be faced with difficulties as shown below. Figure $7 \mathrm{a}$, d shows the typical gradient of Lewy pathology $(\mathrm{dmX}>\mathrm{LC}>\mathrm{SN})$. As fully discussed above, intraneuronal progression starts distally and spreads axonally towards neuronal soma (Fig. 6, orange arrows) in each system. If this regional gradient is mediated by transneuronal spread from $\mathrm{dmX}$ to LC (Fig. 7d, interrupted lines with arrow), aggregated $\alpha \mathrm{S}$ in the $\mathrm{dmX}$ may be taken up by axon terminals and then spreads to the soma of LC neurons. Following transneuronal transfer of aggregated $\alpha \mathrm{S}$ to $\mathrm{LC}$ neurons, it is expected to spread from soma of LC neurons to their distal axons, which is in the direction opposite to what would be occurring in Lewy-prone systems.

Figure 7b, e shows atypical gradient of Lewy pathology $(\mathrm{dmX}<\mathrm{LC}>\mathrm{SN})$. This time, LC neurons are initially involved from its distal axons as expected. When this $\alpha \mathrm{S}$ pathology in LC neuron spreads to $\mathrm{dmX}$ (Fig. 7e), however, the direction of transneuronal spread is reversed (Fig. 7e, asterisk). It remains to be clarified whether the same axonal connection between $\mathrm{dmX}$ and LC could serve as bidirectional conduit or alternative connections are necessary to facilitate this reverse transmission. In either case, transport of $\alpha \mathrm{S}$ aggregates to $\mathrm{dmX}$ soma may induce intraneuronal spread from soma to axon (Fig. 7e, orange arrow). If the regional gradient of $\alpha \mathrm{S}$ lesions of human brain is explained by interneuronal transmission (Fig. $7 \mathrm{~d}-\mathrm{f}$ ), the direction of intraneuronal and that of interneuronal transmission would have to be drastically reversed from a case to another. Although unified hypothesis of conformational template-like propagation may explain spread of $\alpha \mathrm{S}$ lesion and its gradient, we have no unified mechanism to explain how neuroanatomical routes and direction of $\alpha \mathrm{S}$ spread could be so variable at least in the human brain. 
Fig. 7 Non-connected or connected explanations for variable gradient. Relative quantity of Lewy pathology could be quite variable with predominance at the dorsal motor nucleus (dmX, a, d), the locus coeruleus (LC, b, e) or the substantia nigra (SN, c, f). Putative directions of intraneuronal spread for $\alpha \mathrm{S}$ inclusion pathology are indicated with orange or red arrows. Expected directions of possible transneuronal spread of $\alpha \mathrm{S}$ inclusion pathology along interrupted lines are indicated with gray arrows and arrowheads. Either dmX (d), LC (e) or SN (f) is assumed to be initially involved and subsequently spread of $\alpha \mathrm{S}$ inclusion pathology through interneuronal connections. Both intra- and inter-neuronal directions are reversed according to the primary site of involvement (d-f). See text for details
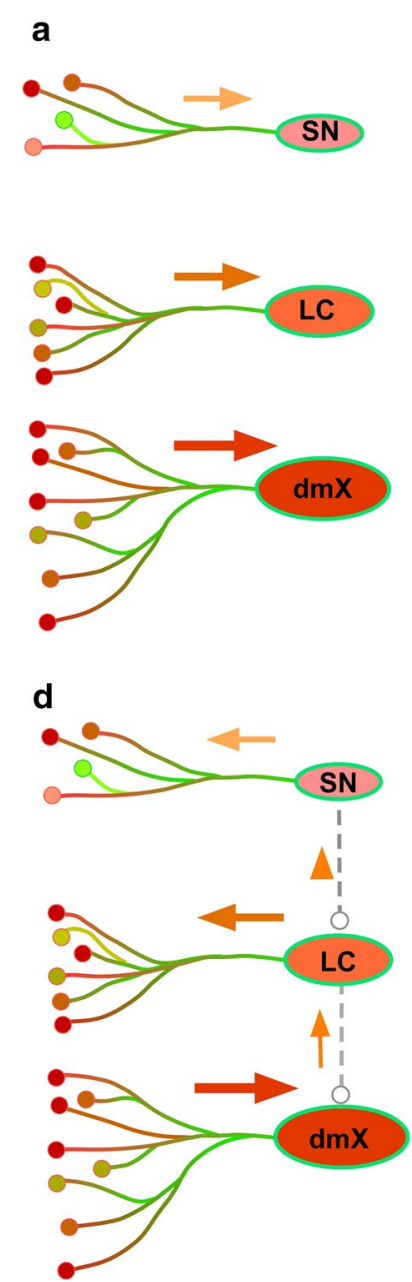

e
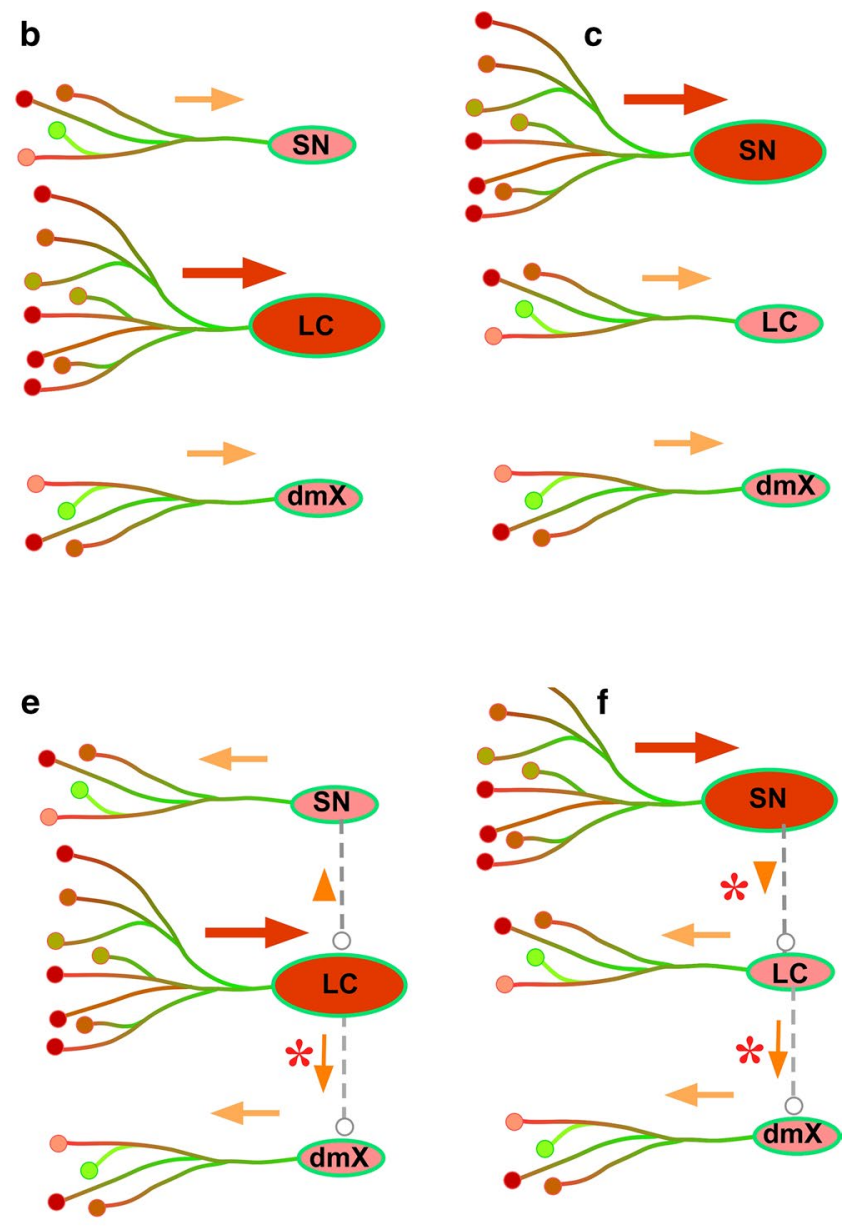

In contrast, Fig. 7a-c shows typical and atypical gradient of LB pathology. Intraneuronal spreads from axon to soma are shared among $\mathrm{dmX}, \mathrm{LC}$ and $\mathrm{SN}$ regardless of the primary site of involvement. Note that this scheme is achieved only when interneuronal connections (interrupted lines in Fig. 7d-f) are eliminated. Because the underlying structures used as anatomopathological substrates for interneuronal connections are not consistent, is it plausible to speculate that each Lewy-prone system could be more or less independent rather than being connected in a predefined order? This hypothesis based on "relative likelihood of different brain regions to manifest Lewy pathology [26]" may better explain why Lewy pathology may not necessarily be in conformity with the ascending spread in the brainstem or sometimes could even be isolated as "focal LB disease". In other words, because the regional abundance of $\alpha \mathrm{S}$ is not homogeneous in the human brain, the relative abundance of $\alpha \mathrm{S}$ inclusion pathology ( $\mathrm{dmX}>\mathrm{LC}>\mathrm{SN}$ ) is not necessarily consistent with a chronological scheme such as staging. Such awareness based on this more flexible hypothesis, in turn, may lead us to reconsider the framework of clinical diagnosis of PD to enhance the clinical recognition of

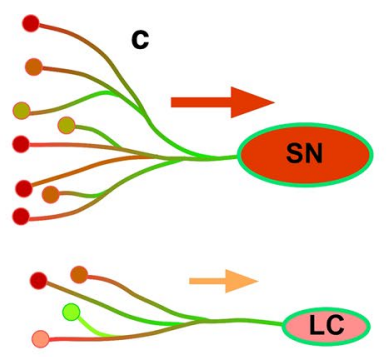

the wider spectrum of LB disease not restricted to PD or DLB [11, 12]. As described above, $\alpha \mathrm{S}$ deposition in some parts of the human brain starts at axon terminals and subsequently spreads along projecting axons toward cell bodies. Unified spread of Lewy pathology from lower brainstem to upper brainstem may only be observed in some selected patients. However, the underlying neuroanatomical map to assure this unidirectional spread is not yet apparent. It is neither demonstrated whether the spread of $\alpha \mathrm{S}$ lesion could be bidirectional (from axon to soma or from soma to axon) in human brain.

Alternatively, or more simply, Lewy pathology at least in the human brain could develop independently even without direct spread between contiguous structures. Such "systemautonomous" development of Lewy pathology is related to the shared "structural template" of thin unmyelinated hyperbranching axon structures that facilitates LB pathology (Figs. 4, 5), which provides the basis for the concept of "focal LB disease". Because development of Lewy pathology is facilitated more or less by such "structural template", gradients in lesion density could be determined by the relative propensity dependent on underlying structures 
(degree of divergence of axon, for example), influence of mitochondrial stress, or energy expenditure.

Of course, this system-autonomous explanation for LB pathology and its regional gradient does not exclude the possibility that transneuronal spreads of $\alpha \mathrm{S}$ deposits and its uptake through neuronal soma are also taking part in human brain with PD. Currently, however, direct evidence to support this transneuronal spread and uptake is not yet clear in human brain with sporadic PD. Even without such transneuronal transmission, gradient of $\alpha \mathrm{S}$ lesion and its variations could be well explained by independent development of $\alpha \mathrm{S}$ lesion in different systems not necessarily linked with each other.

\section{Conclusions}

Many studies and reviews on the topic of neurodegenerative diseases with LBs are organized as if "molecular template" for $\alpha \mathrm{S}$ and its spread along "structural template" are unequivocally coupled to provide a direct mechanism to explain the progressive clinical and pathological nature of these disorders. This coupling of molecular and structural templates may be interesting, convenient and even relevant if both aspects share common molecular processes as at least partially demonstrated in several experimental studies. However, other aberrant mechanisms including neuroimmune activation, injury responses and/or general perturbation of proteostasis, which can also result in promoting the spread of $\alpha \mathrm{S}$ pathology, have also been implicated in these experiments. Furthermore, a direct association between molecular and structural templating as a general unified mechanism for spread of disease along neuropathological pathway would require a strictly directed inter-neuronal transmission (e.g., transsynaptic) of $\alpha \mathrm{S}$ aggregates, but at this time the current experimental studies do not explicitly support this notion. Although this coupling may partially explain stereotyped regional gradient of $\alpha \mathrm{S}$ lesions in human brain, frequently accentuated in lower brainstem and its upward progression, this simplified hypothesis is not sufficient to account for the variable distribution of $\alpha \mathrm{S}$ lesions in human brain ranging from focal LB disease to diffuse LB disease. Multifocal formation of Lewy pathology with variable spreads may better explain the independent occurrence of Lewy pathology in different Lewy-prone systems as "multifocal LB disease". In addition, axonal hyperbranching in combination with other intrinsic cellular properties affecting the abilities of various neurons to cope with misfolded, aggregated $\alpha \mathrm{S}$ could result in neuronal populations with different and unique inherent propensities to internally template $\alpha \mathrm{S}$ amyloid formation. These inherent differences in individual neuronal populations also could partially explain some of the disordered presentation of $\alpha \mathrm{S}$ inclusion pathology in human brains. In contrast with the disordered regional distribution, intraneuronal distribution of Lewy-related degeneration is consistently accentuated at distal axons and retrogradely spreads in an ordered fashion, which is predisposed by their hyperbranching as in the nigrostriatal axons. This order in retrograde spread along hyperbranching axons even in disordered regional distribution of $\alpha \mathrm{S}$ of human brain is representative of Lewy pathology. Awareness of this human brain-oriented view is necessary and helpful not only in modeling the $\alpha \mathrm{S}$ disorders in animals but also in improving clinical practice for better diagnosis and therapy.

Acknowledgments This study was supported by Grants-in-Aid for Scientific Research (JSPS KAKENHI 25430057) from the Ministry of Education, Culture, Sports, Science and Technology; a Grant from the Japan Foundation for Neuroscience and Mental Health, the Mitsui Life Social Welfare Foundation, and the Tokyo Metropolitan Institute of Medical Science project "Mechanism for Early Diagnosis and Prevention of Parkinson's disease" to T.U. This work also was supported by Grants from the NINDS (NS089622) and the National Parkinson Foundation (NPF-UN203) to B.I.G. We are grateful to Ms Emiko Wakatsuki at Tokyo Metropolitan Institute of Medical Science for her excellent art work (Fig. 4).

Open Access This article is distributed under the terms of the Creative Commons Attribution 4.0 International License (http://creativecommons.org/licenses/by/4.0/), which permits unrestricted use, distribution, and reproduction in any medium, provided you give appropriate credit to the original author(s) and the source, provide a link to the Creative Commons license, and indicate if changes were made.

\section{References}

1. Ahn KJ, Paik SR, Chung KC, Kim J (2006) Amino acid sequence motifs and mechanistic features of the membrane translocation of alpha-synuclein. J Neurochem 97(1):265-279

2. Alafuzoff I, Parkkinen L, Al-Sarraj S, Arzberger T, Bell J, Bodi I, Bogdanovic N, Budka H, Ferrer I, Gelpi E, Gentleman S, Giaccone G, Kamphorst W, King A, Korkolopoulou P, Kovacs GG, Larionov S, Meyronet D, Monoranu C, Morris J, Parchi P, Patsouris E, Roggendorf W, Seilhean D, Streichenberger N, Thal DR, Kretzschmar H, BrainNet Europe C (2008) Assessment of alpha-synuclein pathology: a study of the BrainNet Europe Consortium. J Neuropathol Exp Neurol 67(2):125-143. doi:10.1097/nen.0b013e3181633526

3. Anderson JP, Walker DE, Goldstein JM, de Laat R, Banducci K, Caccavello RJ, Barbour R, Huang J, Kling K, Lee M, Diep L, Keim PS, Shen X, Chataway T, Schlossmacher MG, Seubert P, Schenk D, Sinha S, Gai WP, Chilcote TJ (2006) Phosphorylation of ser-129 is the dominant pathological modification of alphasynuclein in familial and sporadic Lewy body disease. J Biol Chem 281(40):29739-29752. doi:10.1074/jbc.M600933200

4. Annerino DM, Arshad S, Taylor GM, Adler CH, Beach TG, Greene JG (2012) Parkinson's disease is not associated with gastrointestinal myenteric ganglion neuron loss. Acta Neuropathol 124(5):665-680. doi:10.1007/s00401-012-1040-2

5. Appel-Cresswell S, Vilarino-Guell C, Encarnacion M, Sherman H, Yu I, Shah B, Weir D, Thompson C, Szu-Tu C, Trinh J, Aasly JO, Rajput A, Rajput AH, Jon SA, Farrer MJ (2013) 
Alpha-synuclein p. H50Q, a novel pathogenic mutation for Parkinson's disease. Mov Disord 28(6):811-813. doi:10.1002/ mds. 25421

6. Barbeau A (1969) L-dopa therapy in Parkinson's disease: a critical review of nine years' experience. Can Med Assoc J 101(13):59-68

7. Beach TG, Adler CH, Sue LI, Vedders L, Lue L, White Iii CL, Akiyama H, Caviness JN, Shill HA, Sabbagh MN, Walker DG, Arizona Parkinson's Disease C (2010) Multi-organ distribution of phosphorylated alpha-synuclein histopathology in subjects with Lewy body disorders. Acta Neuropathol 119(6):689-702. doi:10.1007/s00401-010-0664-3

8. Beach TG, White CL, Hamilton RL, Duda JE, Iwatsubo T, Dickson DW, Leverenz JB, Roncaroli F, Buttini M, Hladik CL, Sue LI, Noorigian JV, Adler CH (2008) Evaluation of alpha-synuclein immunohistochemical methods used by invited experts. Acta Neuropathol 116(3):277-288. doi:10.1007/s00401-008-0409-8

9. Beaulieu JM, Kriz J, Julien JP (2002) Induction of peripherin expression in subsets of brain neurons after lesion injury or cerebral ischemia. Brain Res 946(2):153-161

10. Bellucci A, Navarria L, Zaltieri M, Missale C, Spano P (2012) Alpha-synuclein synaptic pathology and its implications in the development of novel therapeutic approaches to cure Parkinson's disease. Brain Res 1432:95-113. doi:10.1016/j. brainres.2011.11.031

11. Berg D, Lang AE, Postuma RB, Maetzler W, Deuschl G, Gasser T, Siderowf A, Schapira AH, Oertel W, Obeso JA, Olanow CW, Poewe W, Stern M (2013) Changing the research criteria for the diagnosis of Parkinson's disease: obstacles and opportunities. Lancet Neurol 12(5):514-524. doi:10.1016/ S1474-4422(13)70047-4

12. Berg D, Postuma RB, Bloem B, Chan P, Dubois B, Gasser T, Goetz CG, Halliday GM, Hardy J, Lang AE, Litvan I, Marek K, Obeso J, Oertel W, Olanow CW, Poewe W, Stern M, Deuschl G (2014) Time to redefine PD? Introductory statement of the MDS task force on the definition of Parkinson's disease. Mov Disord 29(4):454-462. doi:10.1002/mds. 25844

13. Betemps D, Verchere J, Brot S, Morignat E, Bousset L, Gaillard D, Lakhdar L, Melki R, Baron T (2014) Alpha-synuclein spreading in M83 mice brain revealed by detection of pathological alpha-synuclein by enhanced elisa. Acta Neuropathol Commun 2:29. doi:10.1186/2051-5960-2-29

14. Blesa J, Pifl C, Sanchez-Gonzalez MA, Juri C, Garcia-Cabezas MA, Adanez R, Iglesias E, Collantes M, Penuelas I, SanchezHernandez JJ, Rodriguez-Oroz MC, Avendano C, Hornykiewicz O, Cavada C, Obeso JA (2012) The nigrostriatal system in the presymptomatic and symptomatic stages in the MPTP monkey model: a PET, histological and biochemical study. Neurobiol Dis 48(1):79-91. doi:10.1016/j.nbd.2012.05.018

15. Bloch A, Probst A, Bissig H, Adams H, Tolnay M (2006) Alpha-synuclein pathology of the spinal and peripheral autonomic nervous system in neurologically unimpaired elderly subjects. Neuropathol Appl Neurobiol 32(3):284-295. doi:10.1111/j.1365-2990.2006.00727.x

16. Boeve BF, Silber MH, Ferman TJ, Lin SC, Benarroch EE, Schmeichel AM, Ahlskog JE, Caselli RJ, Jacobson S, Sabbagh M, Adler C, Woodruff B, Beach TG, Iranzo A, Gelpi E, Santamaria J, Tolosa E, Singer C, Mash DC, Luca C, Arnulf I, Duyckaerts C, Schenck CH, Mahowald MW, Dauvilliers Y, GraffRadford NR, Wszolek ZK, Parisi JE, Dugger B, Murray ME, Dickson DW (2013) Clinicopathologic correlations in 172 cases of rapid eye movement sleep behavior disorder with or without a coexisting neurologic disorder. Sleep Med 14(8):754-762. doi:10.1016/j.sleep.2012.10.015

17. Boeve BF, Silber MH, Saper CB, Ferman TJ, Dickson DW, Parisi JE, Benarroch EE, Ahlskog JE, Smith GE, Caselli RC,
Tippman-Peikert M, Olson EJ, Lin SC, Young T, Wszolek Z, Schenck CH, Mahowald MW, Castillo PR, Del Tredici K, Braak H (2007) Pathophysiology of REM sleep behaviour disorder and relevance to neurodegenerative disease. Brain 130(Pt 11):2770-2788. doi:10.1093/brain/awm056

18. Bolam JP, Pissadaki EK (2012) Living on the edge with too many mouths to feed: why dopamine neurons die. Mov Disord 27(12):1478-1483. doi:10.1002/mds.25135

19. Borchelt DR, Davis J, Fischer M, Lee MK, Slunt HH, Ratovitsky T, Regard J, Copeland NG, Jenkins NA, Sisodia SS, Price DL (1996) A vector for expressing foreign genes in the brains and hearts of transgenic mice. Genet Anal 13(6):159-163

20. Braak E, Del Tredici K (2009) Neuroanatomy and pathology of sporadic Parkinson's disease, vol 201., Advances in anatomy, embryology and cell biologySpringer, Berlin

21. Braak H, Bohl JR, Müller CM, Rüb U, de Vos RA, Del Tredici K (2006) Stanley Fahn lecture 2005: the staging procedure for the inclusion body pathology associated with sporadic Parkinson's disease reconsidered. Mov Disord 21(12):2042-2051. doi: $10.1002 / \mathrm{mds} .21065$

22. Braak H, Del Tredici K, Rüb U, de Vos RA, Jansen Steur EN, Braak E (2003) Staging of brain pathology related to sporadic Parkinson's disease. Neurobiol Aging 24(2):197-211

23. Braak H, Sastre M, Bohl JR, de Vos RA, Del Tredici K (2007) Parkinson's disease: lesions in dorsal horn layer I, involvement of parasympathetic and sympathetic pre- and postganglionic neurons. Acta Neuropathol 113(4):421-429. doi:10.1007/ s00401-007-0193-x

24. Braithwaite SP, Stock JB, Mouradian MM (2012) Alphasynuclein phosphorylation as a therapeutic target in Parkinson's disease. Rev Neurosci 23(2):191-198. doi:10.1515/ revneuro-2011-0067

25. Brundin P, Li JY, Holton JL, Lindvall O, Revesz T (2008) Research in motion: the enigma of Parkinson's disease pathology spread. Nat Rev Neurosci 9(10):741-745. doi:10.1038/ nrn2477

26. Burke RE, Dauer WT, Vonsattel JP (2008) A critical evaluation of the Braak staging scheme for Parkinson's disease. Ann Neurol 64(5):485-491. doi:10.1002/ana.21541

27. Burke RE, O'Malley K (2013) Axon degeneration in Parkinson's disease. Exp Neurol 246:72-83. doi:10.1016/j. expneurol.2012.01.011

28. Burre J, Vivona S, Diao J, Sharma M, Brunger AT, Sudhof TC (2013) Properties of native brain alpha-synuclein. Nature 498(7453):E4-E6. doi:10.1038/nature12125

29. Cedarbaum JM, Aghajanian GK (1978) Afferent projections to the rat locus coeruleus as determined by a retrograde tracing technique. J Comp Neurol 178(1):1-16. doi:10.1002/ cne. 901780102

30. Chandra S, Gallardo G, Fernández-Chacón R, Schlüter OM, Südhof TC (2005) Alpha-synuclein cooperates with CSPalpha in preventing neurodegeneration. Cell 123(3):359-361

31. Chartier-Harlin MC, Kachergus J, Roumier C, Mouroux V, Douay X, Lincoln S, Levecque C, Larvor L, Andrieux J, Hulihan M, Waucquier N, Defebvre L, Amouyel P, Farrer M, Destee A (2004) Alpha-synuclein locus duplication as a cause of familial Parkinson's disease. Lancet 364(9440):1167-1169

32. Cheng HC, Ulane CM, Burke RE (2010) Clinical progression in Parkinson disease and the neurobiology of axons. Ann Neurol 67(6):715-725. doi:10.1002/ana.21995

33. Choi W, Zibaee S, Jakes R, Serpell LC, Davletov B, Crowther RA, Goedert M (2004) Mutation E46K increases phospholipid binding and assembly into filaments of human alpha-synuclein. FEBS Lett 576(3):363-368

34. Codolo G, Plotegher N, Pozzobon T, Brucale M, Tessari I, Bubacco L, de Bernard M (2013) Triggering of inflammasome 
by aggregated alpha-synuclein, an inflammatory response in synucleinopathies. PLoS One 8(1):e55375. doi:10.1371/journal. pone. 0055375

35. Conway KA, Harper JD, Lansbury PT (1998) Accelerated in vitro fibril formation by a mutant alpha-synuclein linked to early-onset Parkinson disease. Nat Med 4(11):1318-1320

36. Conway KA, Harper JD, Lansbury PT (2000) Fibrils formed in vitro from alpha-synuclein and two mutant forms linked to Parkinson's disease are typical amyloid. Biochemistry 39(10):2552-2563

37. Conway KA, Lee SJ, Rochet JC, Ding TT, Williamson RE, Lansbury PT (2000) Acceleration of oligomerization, not fibrillization, is a shared property of both alpha-synuclein mutations linked to early-onset Parkinson's disease: implications for pathogenesis and therapy. Proc Natl Acad Sci USA 97(2):571-576

38. Cookson MR (2005) The biochemistry of Parkinson's disease. Annu Rev Biochem 74:29-52

39. Cotzias GC, Papavasiliou PS, Gellene R (1969) Modification of Parkinsonism-chronic treatment with 1-dopa. N Engl J Med 280(7):337-345. doi:10.1056/NEJM196902132800701

40. Cremades N, Cohen SI, Deas E, Abramov AY, Chen AY, Orte A, Sandal M, Clarke RW, Dunne P, Aprile FA, Bertoncini CW, Wood NW, Knowles TP, Dobson CM, Klenerman D (2012) Direct observation of the interconversion of normal and toxic forms of alpha-synuclein. Cell 149(5):1048-1059. doi:10.1016/j.cell.2012.03.037

41. Danzer KM, Kranich LR, Ruf WP, Cagsal-Getkin O, Winslow AR, Zhu L, Vanderburg CR, McLean PJ (2012) Exosomal cellto-cell transmission of alpha synuclein oligomers. Mol Neurodegener 7:42. doi:10.1186/1750-1326-7-42

42. Davidson WS, Jonas A, Clayton DF, George JM (1998) Stabilization of alpha-synuclein secondary structure upon binding to synthetic membranes. J Biol Chem 273(16):9443-9449

43. Del Tredici K, Braak H (2012) Lewy pathology and neurodegeneration in premotor Parkinson's disease. Mov Disord 27(5):597-607. doi:10.1002/mds. 24921

44. Del Tredici K, Braak H (2013) Dysfunction of the locus coeruleus-norepinephrine system and related circuitry in Parkinson's disease-related dementia. J Neurol Neurosurg Psychiatry 84(7):774-783. doi:10.1136/jnnp-2011-301817

45. Del Tredici K, Rüb U, De Vos RA, Bohl JR, Braak H (2002) Where does Parkinson disease pathology begin in the brain? J Neuropathol Exp Neurol 61(5):413-426

46. Diederich NJ, Parent A (2012) Parkinson's disease: acquired frailty of archaic neural networks? J Neurol Sci 314(1-2):143151. doi:10.1016/j.jns.2011.10.003

47. Doppler K, Ebert S, Uceyler N, Trenkwalder C, Ebentheuer J, Volkmann J, Sommer C (2014) Cutaneous neuropathy in Parkinson's disease: a window into brain pathology. Acta Neuropathol 128(1):99-109. doi:10.1007/s00401-014-1284-0

48. Dugger BN, Boeve BF, Murray ME, Parisi JE, Fujishiro H, Dickson DW, Ferman TJ (2012) Rapid eye movement sleep behavior disorder and subtypes in autopsy-confirmed dementia with Lewy bodies. Mov Disord 27(1):72-78. doi:10.1002/ mds. 24003

49. Ebrahimi-Fakhari D, McLean PJ, Unni VK (2012) Alphasynuclein's degradation in vivo: opening a new (cranial) window on the roles of degradation pathways in Parkinson disease. Autophagy 8(2):281-283. doi:10.4161/auto.8.2.18938

50. Ebrahimi-Fakhari D, Saidi LJ, Wahlster L (2013) Molecular chaperones and protein folding as therapeutic targets in Parkinson's disease and other synucleinopathies. Acta Neuropathol Commun 1(1):79. doi:10.1186/2051-5960-1-79

51. El Agnaf OM, Jakes R, Curran MD, Middleton D, Ingenito R, Bianchi E, Pessi A, Neill D, Wallace A (1998) Aggregates from mutant and wild-type alpha-synuclein proteins and NAC peptide induce apoptotic cell death in human neuroblastoma cells by formation of beta-sheet and amyloid-like filaments. FEBS Lett 440(1-2):71-75

52. Eliezer D, Kutluay E, Bussell R Jr, Browne G (2001) Conformational properties of alpha-synuclein in its free and lipid-associated states. J Mol Biol 307(4):1061-1073

53. Emmanouilidou E, Melachroinou K, Roumeliotis T, Garbis SD, Ntzouni M, Margaritis LH, Stefanis L, Vekrellis K (2010) Cellproduced alpha-synuclein is secreted in a calcium-dependent manner by exosomes and impacts neuronal survival. J Neurosci 30(20):6838-6851

54. Emmer KL, Waxman EA, Covy JP, Giasson BI (2011) E46K human alpha-synuclein transgenic mice develop Lewy-like and tau pathology associated with age-dependent, detrimental motor impairment. J Biol Chem 286(40):35104-35118

55. Fares MB, Ait-Bouziad N, Dikiy I, Mbefo MK, Jovicic A, Kiely A, Holton JL, Lee SJ, Gitler AD, Eliezer D, Lashuel HA (2014) The novel Parkinson's disease linked mutation G51D attenuates in vitro aggregation and membrane binding of alpha-synuclein, and enhances its secretion and nuclear localization in cells. Hum Mol Genet 23(17):4491-4509. doi:10.1093/hmg/ddu 165

56. Farrer M, Kachergus J, Forno L, Lincoln S, Wang DS, Hulihan M, Maraganore D, Gwinn-Hardy K, Wszolek Z, Dickson D, Langston JW (2004) Comparison of kindreds with Parkinsonism and alpha-synuclein genomic multiplications. Ann Neurol 55(2):174-179

57. Fortin DL, Nemani VM, Edwards RH (2008) A-synuclein, CSPa, SNAREs and neuroprotection in vivo. In: Naas R, Przedborski S (eds) Parkinson's disease: molecular and therapeutic insights from model systems, 1st edn. Academic Press, Waltham, pp 237-246

58. Freundt EC, Maynard N, Clancy EK, Roy S, Bousset L, Sourigues Y, Covert M, Melki R, Kirkegaard K, Brahic M (2012) Neuronto-neuron transmission of alpha-synuclein fibrils through axonal transport. Ann Neurol 72(4):517-524. doi:10.1002/ana.23747

59. Fujiwara H, Hasegawa M, Dohmae N, Kawashima A, Masliah E, Goldberg MS, Shen J, Takio K, Iwatsubo T (2002) A-synuclein is phosphorylated in synucleinopathy lesions. Nat Cell Biol 4:160-164

60. George JM, Jin H, Woods WS, Clayton DF (1995) Characterization of a novel protein regulated during the critical period for song learning in the zebra finch. Neuron 15(2):361-372

61. Ghosh D, Mondal M, Mohite GM, Singh PK, Ranjan P, Anoop A, Ghosh S, Jha NN, Kumar A, Maji SK (2013) The Parkinson's disease-associated H50Q mutation accelerates alphasynuclein aggregation in vitro. Biochemistry 52(40):69256927. doi:10.1021/bi400999d

62. Ghosh D, Sahay S, Ranjan P, Salot S, Mohite GM, Singh PK, Dwivedi S, Carvalho E, Banerjee R, Kumar A, Maji SK (2014) The newly discovered Parkinson's disease associated Finnish mutation (A53E) attenuates alpha-synuclein aggregation and membrane binding. Biochemistry 53(41):6419-6421. doi:10.1021/bi5010365

63. Giasson BI, Duda JE, Forman MS, Lee VM-Y, Trojanoswki JQ (2001) Prominent perikaryal expression of $\alpha$ - and $\beta$-synuclein in neurons of dorsal root ganglion and in medullary neurons. Exp Neurol 172:354-362

64. Giasson BI, Duda JE, Quinn SM, Zhang B, Trojanowski JQ, Lee VM (2002) Neuronal alpha-synucleinopathy with severe movement disorder in mice expressing A53T human alphasynuclein. Neuron 34(4):521-533

65. Giasson BI, Lee VM-Y (2003) Are ubiquitination pathways central to Parkinson's disease? Cell 114:1-8

66. Giasson BI, Murray IV, Trojanowski JQ, Lee VM-Y (2001) A hydrophobic stretch of 12 amino acid residues in the middle of 
alpha-synuclein is essential for filament assembly. J Biol Chem 276:2380-2386

67. Giasson BI, Uryu K, Trojanowski JQ, Lee VM-Y (1999) Mutant and wild type human alpha-synucleins assemble into elongated filaments with distinct morphologies in vitro. J Biol Chem 274(12):7619-7622

68. Goedert M (2001) Alpha-synuclein and neurodegenerative diseases. Nat Rev Neurosci 2:492-501

69. Goedert M, Spillantini MG, Del Tredici K, Braak H (2013) 100 years of Lewy pathology. Nat Rev Neurol 9(1):13-24. doi:10.1038/nrneurol.2012.242

70. Golde TE, Borchelt DR, Giasson BI, Lewis J (2013) Thinking laterally about neurodegenerative proteinopathies. J Clin Invest 123:1847-1855

71. Goldman JE, Yen SH, Chiu FC, Peress NS (1983) Lewy bodies of Parkinson's disease contain neurofilament antigens. Science 221(4615):1082-1084

72. Greenbaum EA, Graves CL, Mishizen-Eberz AJ, Lupoli MA, Lynch DR, Englander SW, Axelsen PH, Giasson BI (2005) The E46K mutation in alpha -synuclein increases amyloid fibril formation. J Biol Chem 280(9):7800-7807

73. Greenfield JG, Bosanquet FD (1953) The brain-stem lesions in parkinsonism. J Neurol Neurosurg Psychiatry 16(4):213-226

74. Greffard S, Verny M, Bonnet AM, Seilhean D, Hauw JJ, Duyckaerts C (2010) A stable proportion of Lewy body bearing neurons in the substantia nigra suggests a model in which the Lewy body causes neuronal death. Neurobiol Aging 31(1):99-103. doi:10.1016/j.neurobiolaging.2008.03.015

75. Guo JL, Covell DJ, Daniels JP, Iba M, Stieber A, Zhang B, Riddle DM, Kwong LK, Xu Y, Trojanowski JQ, Lee VM (2013) Distinct alpha-synuclein strains differentially promote tau inclusions in neurons. Cell 154(1):103-117. doi:10.1016/j. cell.2013.05.057

76. Haelterman NA, Yoon WH, Sandoval H, Jaiswal M, Shulman JM, Bellen HJ (2014) A mitocentric view of Parkinson's disease. Annu Rev Neurosci 37:137-159. doi:10.1146/ annurev-neuro-071013-014317

77. Hague K, Lento P, Morgello S, Caro S, Kaufmann H (1997) The distribution of Lewy bodies in pure autonomic failure: autopsy findings and review of the literature. Acta Neuropathol 94(2):192-196

78. Halliday G, Hely M, Reid W, Morris J (2008) The progression of pathology in longitudinally followed patients with Parkinson's disease. Acta Neuropathol 115(4):409-415. doi:10.1007/ s00401-008-0344-8

79. Hashimoto M, Hsu LJ, Sisk A, Xia Y, Takeda A, Sundsmo M, Masliah E (1998) Human recombinant NACP/alpha-synuclein is aggregated and fibrillated in vitro: relevance for Lewy body disease. Brain Res 799(2):301-306

80. Hauser DN, Hastings TG (2013) Mitochondrial dysfunction and oxidative stress in Parkinson's disease and monogenic parkinsonism. Neurobiol Dis 51:35-42. doi:10.1016/j. nbd.2012.10.011

81. Hawkes CH, Del Tredici K, Braak H (2007) Parkinson's disease: a dual-hit hypothesis. Neuropathol Appl Neurobiol 33(6):599-614. doi:10.1111/j.1365-2990.2007.00874.x

82. Henderson JM, Carpenter K, Cartwright H, Halliday GM (2000) Degeneration of the centre median-parafascicular complex in Parkinson's disease. Ann Neurol 47(3):345-352

83. Hilton D, Stephens M, Kirk L, Edwards P, Potter R, Zajicek J, Broughton E, Hagan H, Carroll C (2014) Accumulation of alpha-synuclein in the bowel of patients in the pre-clinical phase of Parkinson's disease. Acta Neuropathol 127(2):235241. doi:10.1007/s00401-013-1214-6

84. Höglinger GU, Alvarez-Fischer D, Arias-Carrión O, Djufri M, Windolph A, Keber U, Borta A, Ries V, Schwarting RK, Scheller
D, Oertel WH (2015) A new dopaminergic nigro-olfactory projection. Acta Neuropathol. doi:10.1007/s00401-015-1451-y

85. Hornykiewicz O (1998) Biochemical aspects of Parkinson's disease. Neurology 51(2 Suppl 2):S2-S9

86. Howlett DR, Whitfield D, Johnson M, Attems J, O'Brien JT, Aarsland D, Lai MK, Lee JH, Chen C, Ballard C, Hortobagyi T, Francis PT (2015) Regional multiple pathology scores are associated with cognitive decline in Lewy body dementias. Brain Pathol 25(4):401-408. doi:10.1111/bpa.12182

87. Irizarry MC, Kim TW, McNamara M, Tanzi RE, George JM, Clayton DF, Hyman BT (1996) Characterization of the precursor protein of the non-A beta component of senile plaques (NACP) in the human central nervous system. J Neuropathol Exp Neurol 55(8):889-895

88. Iwai A, Masliah E, Yoshimoto M, Ge N, Flanagan L, de Silva HA, Kittel A, Saitoh T (1995) The precursor protein of non-A beta component of Alzheimer's disease amyloid is a presynaptic protein of the central nervous system. Neuron 14(2):467-475

89. Jakes R, Spillantini MG, Goedert M (1994) Identification of two distinct synucleins from human brain. FEBS Lett 345(1):27-32

90. Jellinger KA (2012) Neuropathology of sporadic Parkinson's disease: evaluation and changes of concepts. Mov Disord 27(1):8-30. doi:10.1002/mds.23795

91. Kalaitzakis ME, Graeber MB, Gentleman SM, Pearce RK (2008) Controversies over the staging of alpha-synuclein pathology in Parkinson's disease. Acta Neuropathol 116(1):125-128. doi:10.1007/s00401-008-0381-3

92. Kanazawa T, Adachi E, Orimo S, Nakamura A, Mizusawa H, Uchihara T (2012) Pale neurites, premature alpha-synuclein aggregates with centripetal extension from axon collaterals. Brain Pathol 22(1):67-78. doi:10.1111/j.1750-3639.2011.00509.x

93. Kanazawa T, Uchihara T, Takahashi A, Nakamura A, Orimo S, Mizusawa H (2008) Three-layered structure shared between Lewy bodies and Lewy neurites-three-dimensional reconstruction of triple-labeled sections. Brain Pathol 18(3):415-422. doi:10.1111/j.1750-3639.2008.00140.x

94. Kayed R, Head E, Thompson JL, McIntire TM, Milton SC, Cotman CW, Glabe CG (2003) Common structure of soluble amyloid oligomers implies common mechanism of pathogenesis. Science 300(5618):486-489

95. Khalaf O, Fauvet B, Oueslati A, Dikiy I, Mahul-Mellier AL, Ruggeri FS, Mbefo MK, Vercruysse F, Dietler G, Lee SJ, Eliezer D, Lashuel HA (2014) The H50Q mutation enhances alpha-synuclein aggregation, secretion, and toxicity. J Biol Chem 289(32):21856-21876. doi:10.1074/jbc.M114.553297

96. Kiely AP, Asi YT, Kara E, Limousin P, Ling H, Lewis P, Proukakis C, Quinn N, Lees AJ, Hardy J, Revesz T, Houlden H, Holton JL (2013) Alpha-synucleinopathy associated with G51D SNCA mutation: a link between Parkinson's disease and multiple system atrophy? Acta Neuropathol 125(5):753-769. doi:10.1007/ s00401-013-1096-7

97. Kim C, Ho DH, Suk JE, You S, Michael S, Kang J, Joong LS, Masliah E, Hwang D, Lee HJ, Lee SJ (2013) Neuron-released oligomeric alpha-synuclein is an endogenous agonist of TLR2 for paracrine activation of microglia. Nat Commun 4:1562. doi: $10.1038 /$ ncomms 2534

98. Kim YS, Laurine E, Woods W, Lee SJ (2006) A novel mechanism of interaction between alpha-synuclein and biological membranes. J Mol Biol 360(2):386-397. doi:10.1016/j. jmb.2006.05.004

99. Kirik D, Annett LE, Burger C, Muzyczka N, Mandel RJ, Bjorklund A (2003) Nigrostriatal alpha-synucleinopathy induced by viral vector-mediated overexpression of human alpha-synuclein: a new primate model of Parkinson's disease. Proc Natl Acad Sci USA 100(5):2884-2889. doi:10.1073/ pnas. 0536383100 
100. Kirik D, Rosenblad C, Burger C, Lundberg C, Johansen TE, Muzyczka N, Mandel RJ, Bjorklund A (2002) Parkinsonlike neurodegeneration induced by targeted overexpression of alpha-synuclein in the nigrostriatal system. J Neurosci 22(7):2780-2791

101. Klein RL, King MA, Hamby ME, Meyer EM (2002) Dopaminergic cell loss induced by human A30P alpha-synuclein gene transfer to the rat substantia nigra. Hum Gene Ther 13(5):605612. doi:10.1089/10430340252837206

102. Kosaka K (1978) Lewy bodies in cerebral cortex, report of three cases. Acta Neuropathol 42(2):127-134

103. Kosaka K, Iseki E, Odawara T, Yamamoto T (1996) Cerebral type of Lewy body disease. Neuropathology 16:32-35

104. Kovacs GG, Alafuzoff I, Al-Sarraj S, Arzberger T, Bogdanovic N, Capellari S, Ferrer I, Gelpi E, Kovari V, Kretzschmar H, Nagy Z, Parchi P, Seilhean D, Soininen H, Troakes C, Budka H (2008) Mixed brain pathologies in dementia: the BrainNet Europe consortium experience. Dement Geriatr Cogn Disord 26(4):343-350. doi:10.1159/000161560

105. Kovacs GG, Wagner U, Dumont B, Pikkarainen M, Osman AA, Streichenberger N, Leisser I, Verchere J, Baron T, Alafuzoff I, Budka H, Perret-Liaudet A, Lachmann I (2012) An antibody with high reactivity for disease-associated alpha-synuclein reveals extensive brain pathology. Acta Neuropathol 124(1):3750. doi:10.1007/s00401-012-0964-x

106. Kramer ML, Schulz-Schaeffer WJ (2007) Presynaptic alphasynuclein aggregates, not Lewy bodies, cause neurodegeneration in dementia with Lewy bodies. J Neurosci 27(6):14051410. doi:10.1523/JNEUROSCI.4564-06.2007

107. Krüger R, Kuhn W, Müller T, Woitalla D, Graeber M, Kosel S, Przuntek H, Epplen JT, Schöls L, Riess O (1998) Ala30Pro mutation in the gene encoding alpha-synuclein in Parkinson's disease. Nat Genet 18(2):106-108

108. Lee HJ, Khoshaghideh F, Patel S, Lee SJ (2004) Clearance of alpha-synuclein oligomeric intermediates via the lysosomal degradation pathway. J Neurosci 24(8):1888-1896. doi:10.1523/JNEUROSCI.3809-03.2004

109. Lee HJ, Patel S, Lee SJ (2005) Intravesicular localization and exocytosis of alpha-synuclein and its aggregates. J Neurosci 25(25):6016-6024

110. Lee HJ, Suk JE, Bae EJ, Lee JH, Paik SR, Lee SJ (2008) Assembly-dependent endocytosis and clearance of extracellular alpha-synuclein. Int J Biochem Cell Biol 40(9):1835-1849

111. Lee HJ, Suk JE, Bae EJ, Lee SJ (2008) Clearance and deposition of extracellular alpha-synuclein aggregates in microglia. Biochem Biophys Res Commun 372(3):423-428. doi:10.1016/j. bbrc.2008.05.045

112. Lee HJ, Suk JE, Patrick C, Bae EJ, Cho JH, Rho S, Hwang D, Masliah E, Lee SJ (2010) Direct transfer of alpha-synuclein from neuron to astroglia causes inflammatory responses in synucleinopathies. J Biol Chem 285(12):9262-9272

113. Lees AJ (2009) The Parkinson chimera. Neurology $72(7$ Suppl):S2-S11. doi:10.1212/WNL.0b013e318198daec

114. Lees AJ, Selikhova M, Andrade LA, Duyckaerts C (2008) The black stuff and Konstantin Nikolaevich Tretiakoff. Mov Disord 23(6):777-783. doi:10.1002/mds.21855

115. Lema Tomé CM, Tyson T, Rey NL, Grathwohl S, Britschgi M, Brundin P (2013) Inflammation and alpha-synuclein's prionlike behavior in Parkinson's disease-is there a link? Mol Neurobiol 47(2):561-574. doi:10.1007/s12035-012-8267-8

116. Lesage S, Anheim M, Letournel F, Bousset L, Honore A, Rozas N, Pieri L, Madiona K, Dürr A, Melki R, Verny C, Brice A (2013) G51D alpha-synuclein mutation causes a novel Parkinsonian-pyramidal syndrome. Ann Neurol 73(4):459-471. doi:10.1002/ana.23894
117. Lesuisse C, Xu G, Anderson J, Wong M, Jankowsky J, Holtz G, Gonzalez V, Wong PC, Price DL, Tang F, Wagner S, Borchelt DR (2001) Hyper-expression of human apolipoprotein E4 in astroglia and neurons does not enhance amyloid deposition in transgenic mice. Hum Mol Genet 10(22):2525-2537

118. Li J, Uversky VN, Fink AL (2001) Effect of familial Parkinson's disease point mutations A30P and A53T on the structural properties, aggregation, and fibrillation of human alpha-synuclein. Biochemistry 40(38):11604-11613

119. Lingor P, Koch JC, Tonges L, Bahr M (2012) Axonal degeneration as a therapeutic target in the CNS. Cell Tissue Res 349(1):289-311. doi:10.1007/s00441-012-1362-3

120. Liu CW, Giasson BI, Lewis KA, Lee VM, Demartino GN, Thomas PJ (2005) A precipitating role for truncated alphasynuclein and the proteasome in alpha-synuclein aggregation: implications for pathogenesis of Parkinson disease. J Biol Chem 280(24):22670-22678. doi:10.1074/jbc.M501508200

121. Liu J, Zhang JP, Shi M, Quinn T, Bradner J, Beyer R, Chen S, Zhang J (2009) Rab11a and hsp90 regulate recycling of extracellular alpha-synuclein. J Neurosci 29(5):1480-1485

122. Lo Bianco C, Ridet JL, Schneider BL, Deglon N, Aebischer P (2002) Alpha-synucleinopathy and selective dopaminergic neuron loss in a rat lentiviral-based model of Parkinson's disease. Proc Natl Acad Sci USA 99(16):10813-10818. doi:10.1073/ pnas.152339799

123. Louis ED, Honig LS, Vonsattel JP, Maraganore DM, Borden S, Moskowitz CB (2005) Essential tremor associated with focal nonnigral Lewy bodies: a clinicopathologic study. Arch Neurol 62(6):1004-1007. doi:10.1001/archneur.62.6.1004

124. Luk KC, Kehm V, Carroll J, Zhang B, O'Brien P, Trojanowski JQ, Lee VM (2012) Pathological alpha-synuclein transmission initiates Parkinson-like neurodegeneration in nontransgenic mice. Science 338(6109):949-953. doi:10.1126/ science. 1227157

125. Luk KC, Kehm VM, Zhang B, O’Brien P, Trojanowski JQ, Lee VM (2012) Intracerebral inoculation of pathological alphasynuclein initiates a rapidly progressive neurodegenerative alpha-synucleinopathy in mice. J Exp Med 209(5):975-986. doi:10.1084/jem.20112457

126. Luk KC, Song C, O'Brien P, Stieber A, Branch JR, Brunden KR, Trojanowski JQ, Lee VM (2009) Exogenous alpha-synuclein fibrils seed the formation of Lewy body-like intracellular inclusions in cultured cells. Proc Natl Acad Sci USA 106(47):20051-20056

127. Manzoni C, Lewis PA (2013) Dysfunction of the autophagy/lysosomal degradation pathway is a shared feature of the genetic synucleinopathies. FASEB J 27(9):3424-3429. doi:10.1096/ fj. $12-223842$

128. Martin I, Dawson VL, Dawson TM (2011) Recent advances in the genetics of Parkinson's disease. Annu Rev Genomics Hum Genet 12:301-325. doi:10.1146/ annurev-genom-082410-101440

129. Masuda-Suzukake M, Nonaka T, Hosokawa M, Kubo M, Shimozawa A, Akiyama H, Hasegawa M (2014) Pathological alpha-synuclein propagates through neural networks. Acta Neuropathol Commun 2:88. doi:10.1186/s40478-014-0088-8

130. Masuda-Suzukake M, Nonaka T, Hosokawa M, Oikawa T, Arai T, Akiyama H, Mann DM, Hasegawa M (2013) Prionlike spreading of pathological alpha-synuclein in brain. Brain 136(Pt 4):1128-1138. doi:10.1093/brain/awt037

131. Matsuda W, Furuta T, Nakamura KC, Hioki H, Fujiyama F, Arai R, Kaneko T (2009) Single nigrostriatal dopaminergic neurons form widely spread and highly dense axonal arborizations in the neostriatum. J Neurosci 29(2):444-453. doi:10.1523/ JNEUROSCI.4029-08.2009 
132. McCann H, Stevens CH, Cartwright H, Halliday GM (2014) A-synucleinopathy phenotypes. Parkinsonism Relat Disord 20:S62-S67. doi:10.1016/s1353-8020(13)70017-8

133. Miki Y, Mori F, Wakabayashi K, Kuroda N, Orimo S (2009) Incidental Lewy body disease restricted to the heart and stellate ganglia. Mov Disord 24(15):2299-2301. doi:10.1002/ mds. 22775

134. Miller DW, Johnson JM, Solano SM, Hollingsworth ZR, Standaert DG, Young AB (2005) Absence of alpha-synuclein mRNA expression in normal and multiple system atrophy oligodendroglia. J Neural Transm 112(12):1613-1624. doi:10.1007/ s00702-005-0378-1

135. Minguez-Castellanos A, Chamorro CE, Escamilla-Sevilla F, Ortega-Moreno A, Rebollo AC, Gomez-Rio M, Concha A, Munoz DG (2007) Do alpha-synuclein aggregates in autonomic plexuses predate Lewy body disorders?: a cohort study. Neurology 68(23):2012-2018. doi:10.1212/01. wnl.0000264429.59379.d9

136. Mizuno Y, Hattori N, Mochizuki H (2007) Genetic aspects of Parkinson's disease. Handb Clin Neurol 83:217-244. doi:10.1016/s0072-9752(07)83009-0

137. Mougenot AL, Nicot S, Bencsik A, Morignat E, Verchere J, Lakhdar L, Legastelois S, Baron T (2012) Prion-like acceleration of a synucleinopathy in a transgenic mouse model. Neurobiol Aging 33(9):2225-2228. doi:10.1016/j. neurobiolaging.2011.06.022

138. Narhi L, Wood SJ, Steavenson S, Jiang Y, Wu GM, Anafi D, Kaufman SA, Martin F, Sitney K, Denis P, Louis JC, Wypych J, Biere AL, Citron M (1999) Both familial Parkinson's disease mutations accelerate alpha-synuclein aggregation. J Biol Chem 274(14):9843-9846

139. Nolte J, Angevine JB (2007) The human brain in photographs and diagrams, 3rd edn. Mosby/Elsevier, Philadelphia

140. Nonaka T, Watanabe ST, Iwatsubo T, Hasegawa M (2010) Seeded aggregation and toxicity of alpha-synuclein and tau: cellular models of neurodegenerative diseases. J Biol Chem 285(45):34885-34898. doi:10.1074/jbc.M110.148460

141. Okazaki H, Lipkin LE, Aronson SM (1961) Diffuse intracytoplasmic ganglionic inclusions (Lewy type) associated with progressive dementia and quadriparesis in flexion. J Neuropathol Exp Neurol 20:237-244

142. Orimo S, Suzuki M, Inaba A, Mizusawa H (2012) 123I-MIBG myocardial scintigraphy for differentiating Parkinson's disease from other neurodegenerative Parkinsonism: a systematic review and meta-analysis. Parkinsonism Relat Disord 18(5):494-500. doi:10.1016/j.parkreldis.2012.01.009

143. Orimo S, Uchihara T, Nakamura A, Mori F, Kakita A, Wakabayashi K, Takahashi H (2008) Axonal alpha-synuclein aggregates herald centripetal degeneration of cardiac sympathetic nerve in Parkinson's disease. Brain 131(Pt 3):642-650. doi:10.1093/brain/awm302

144. Parkkinen L, Pirttila T, Alafuzoff I (2008) Applicability of current staging/categorization of alpha-synuclein pathology and their clinical relevance. Acta Neuropathol 115(4):399-407. doi:10.1007/s00401-008-0346-6

145. Pasanen P, Myllykangas L, Siitonen M, Raunio A, Kaakkola S, Lyytinen J, Tienari PJ, Poyhonen M, Paetau A (2014) Novel alpha-synuclein mutation A53E associated with atypical multiple system atrophy and Parkinson's disease-type pathology. Neurobiol Aging 35(9):2180-2185. doi:10.1016/j. neurobiolaging.2014.03.024

146. Paumier KL, Luk KC, Manfredsson FP, Kanaan NM, Lipton JW, Collier TJ, Steece-Collier K, Kemp CJ, Celano S, Schulz E, Sandoval IM, Fleming S, Dirr E, Polinski NK, Trojanowski JQ, Lee VM, Sortwell CE (2015) Intrastriatal injection of pre-formed mouse alpha-synuclein fibrils into rats triggers alpha-synuclein pathology and bilateral nigrostriatal degeneration. Neurobiol Dis 82:185-199. doi:10.1016/j.nbd.2015.06.003

147. Peelaerts W, Bousset L, Van der Perren A, Moskalyuk A, Pulizzi R, Giugliano M, Van den Haute C, Melki R, Baekelandt V (2015) Alpha-synuclein strains cause distinct synucleinopathies after local and systemic administration. Nature 522(7556):340344. doi:10.1038/nature 14547

148. Pikkarainen M, Martikainen P, Alafuzoff I (2010) The effect of prolonged fixation time on immunohistochemical staining of common neurodegenerative disease markers. J Neuropathol Exp Neurol 69(1):40-52. doi:10.1097/NEN.0b013e3181c6c13d

149. Pissadaki EK, Bolam JP (2013) The energy cost of action potential propagation in dopamine neurons: clues to susceptibility in Parkinson's disease. Front Comput Neurosci 7:13. doi:10.3389/fncom.2013.00013

150. Polymeropoulos MH, Lavedan C, Leroy E, Ide SE, Dehejia A, Dutra A, Pike B, Root H, Rubenstein J, Boyer R, Stenroos ES, Chandrasekharappa S, Athanassiadou A, Papapetropoulos T, Johnson WG, Lazzarini AM, Duvoisin RC, Di Iorio G, Golbe LI, Nussbaum RL (1997) Mutation in the alpha-synuclein gene identified in families with Parkinson's disease. Science 276(5321):2045-2047

151. Proukakis C, Dudzik CG, Brier T, Mackay DS, Cooper JM, Millhauser GL, Houlden H, Schapira AH (2013) A novel alphasynuclein missense mutation in Parkinson disease. Neurology 80(11):1062-1064. doi:10.1212/WNL.0b013e31828727ba

152. Recasens A, Dehay B, Bove J, Carballo-Carbajal I, Dovero S, Perez-Villalba A, Fernagut PO, Blesa J, Parent A, Perier C, Farinas I, Obeso JA, Bezard E, Vila M (2014) Lewy body extracts from Parkinson disease brains trigger alpha-synuclein pathology and neurodegeneration in mice and monkeys. Ann Neurol 75(3):351-362. doi:10.1002/ana.24066

153. Rey NL, Petit GH, Bousset L, Melki R, Brundin P (2013) Transfer of human alpha-synuclein from the olfactory bulb to interconnected brain regions in mice. Acta Neuropathol 126(4):555-573. doi:10.1007/s00401-013-1160-3

154. Reyes JF, Rey NL, Bousset L, Melki R, Brundin P, Angot E (2013) Alpha-synuclein transfers from neurons to oligodendrocytes. Glia 62(3):387-398. doi:10.1002/glia.22611

155. Roberts RF, Wade-Martins R, Alegre-Abarrategui J (2015) Direct visualization of alpha-synuclein oligomers reveals previously undetected pathology in Parkinson's disease brain. Brain 138(Pt 6):1642-1657. doi:10.1093/brain/awv040

156. Roodveldt C, Christodoulou J, Dobson CM (2008) Immunological features of alpha-synuclein in Parkinson's disease. J Cell Mol Med 12(5B):1820-1829

157. Rutherford NJ, Giasson BI (2015) The A53E alpha-synuclein pathological mutation demonstrates reduced aggregation propensity in vitro and in cell culture. Neurosci Lett 597:43-48. doi:10.1016/j.neulet.2015.04.022

158. Rutherford NJ, Moore BD, Golde TE, Giasson BI (2014) Divergent effects of the H50Q and G51D SNCA mutations on the aggregation of alpha-synuclein. J Neurochem 131(6):859-867. doi:10.1111/jnc. 12806

159. Sacino AN, Brooks M, McGarvey NH, McKinney AB, Thomas MA, Levites Y, Ran Y, Golde TE, Giasson BI (2013) Induction of CNS alpha-synuclein pathology by fibrillar and non-amyloidogenic recombinant alpha-synuclein. Acta Neuropathol Commun 1(1):38. doi:10.1186/2051-5960-1-38

160. Sacino AN, Brooks M, McKinney AB, Thomas MA, Shaw G, Golde TE, Giasson BI (2014) Brain injection of alpha-synuclein induces multiple proteinopathies, gliosis, and a neuronal injury marker. J Neurosci 34(37):12368-12378. doi:10.1523/ JNEUROSCI.2102-14.2014

161. Sacino AN, Brooks M, Thomas MA, McKinney AB, Lee S, Regenhardt RW, McGarvey NH, Ayers JI, Notterpek L, 
Borchelt DR, Golde TE, Giasson BI (2014) Intramuscular injection of alpha-synuclein induces CNS alpha-synuclein pathology and a rapid-onset motor phenotype in transgenic mice. Proc Natl Acad Sci USA 111(29):10732-10737. doi:10.1073/ pnas. 1321785111

162. Sacino AN, Brooks M, Thomas MA, McKinney AB, McGarvey NH, Rutherford NJ, Ceballos-Diaz C, Robertson J, Golde TE, Giasson BI (2014) Amyloidogenic alpha-synuclein seeds do not invariably induce rapid, widespread pathology in mice. Acta Neuropathol 127(7):645-665. doi:10.1007/s00401-014-1268-0

163. Sacino AN, Thomas MA, Ceballos-Diaz C, Cruz PE, Rosario AM, Lewis J, Giasson BI, Golde TE (2013) Conformational templating of alpha-synuclein aggregates in neuronal-glial cultures. Mol Neurodegener 8:17. doi:10.1186/1750-1326-8-17

164. Sano I, Taniguchi K, Gamo T, Takesada M, Kakimoto $Y$ (1960) Die Katechinamine im Zentralnervensystem. Klinische Wochenschrift 38:57-62

165. Schweighauser M, Bacioglu M, Fritschi SK, Shimshek DR, Kahle PJ, Eisele YS, Jucker M (2015) Formaldehyde-fixed brain tissue from spontaneously ill alpha-synuclein transgenic mice induces fatal alpha-synucleinopathy in transgenic hosts. Acta Neuropathol 129(1):157-159. doi:10.1007/s00401-014-1360-5

166. Serpell LC, Berriman J, Jakes R, Goedert M, Crowther RA (2000) Fiber diffraction of synthetic alpha-synuclein filaments shows amyloid-like cross-beta conformation. Proc Natl Acad Sci USA 97(9):4897-4902

167. Singleton AB, Farrer M, Johnson J, Singleton A, Hague S, Kachergus J, Hulihan M, Peuralinna T, Dutra A, Nussbaum R, Lincoln S, Crawley A, Hanson M, Maraganore D, Adler C, Cookson MR, Muenter M, Baptista M, Miller D, Blancato J, Hardy J, Gwinn-Hardy K (2003) Alpha-synuclein locus triplication causes Parkinson's disease. Science 302(5646):841

168. Spillantini MG, Schmidt ML, Lee VM, Trojanowski JQ, Jakes R, Goedert M (1997) Alpha-synuclein in Lewy bodies. Nature 388(6645):839-840. doi:10.1038/42166

169. Subramaniam SR, Chesselet MF (2013) Mitochondrial dysfunction and oxidative stress in parkinson's disease. Prog Neurobiol 106-107:17-32. doi:10.1016/j.pneurobio.2013.04.004

170. Sulzer D, Surmeier DJ (2013) Neuronal vulnerability, pathogenesis, and Parkinson's disease. Mov Disord 28(1):41-50. doi: $10.1002 / \mathrm{mds} .25095$

171. Sung JY, Kim J, Paik SR, Park JH, Ahn YS, Chung KC (2001) Induction of neuronal cell death by Rab5a-dependent endocytosis of alpha-synuclein. J Biol Chem 276(29):27441-27448. doi:10.1074/jbc.M101318200

172. Takahashi M, Ikemura M, Oka T, Uchihara T, Wakabayashi K, Kakita A, Takahashi H, Yoshida M, Toru S, Kobayashi T, Orimo S (2015) Quantitative correlation between cardiac MIBG uptake and remaining axons in the cardiac sympathetic nerve in Lewy body disease. J Neurol Neurosurg Psychiatry 86(9):939-944. doi:10.1136/jnnp-2015-310686

173. Tran HT, Chung $\mathrm{CH}$, Iba M, Zhang B, Trojanowski JQ, Luk KC, Lee VM (2014) Alpha-synuclein immunotherapy blocks uptake and templated propagation of misfolded alphasynuclein and neurodegeneration. Cell Rep 7(6):2054-2065. doi:10.1016/j.celrep.2014.05.033

174. Ubeda-Banon I, Saiz-Sanchez D, de la Rosa-Prieto C, Martinez-Marcos A (2014) Alpha-synuclein in the olfactory system in Parkinson's disease: role of neural connections on spreading pathology. Brain Struct Funct 219(5):1513-1526. doi:10.1007/ s00429-013-0651-2

175. Uchihara T (2007) Silver diagnosis in neuropathology: principles, practice and revised interpretation. Acta Neuropathol 113(5):483-499. doi:10.1007/s00401-007-0200-2

176. Ulusoy A, Rusconi R, Perez-Revuelta BI, Musgrove RE, Helwig M, Winzen-Reichert B, Di Monte DA (2013)
Caudo-rostral brain spreading of alpha-synuclein through vagal connections. EMBO Mol Med 5(7):1051-1059. doi:10.1002/ emmm. 201302475

177. Uversky VN, Li J, Fink AL (2001) Evidence for a partiallyfolded intermediate in alpha-synuclein fibril formation. J Biol Chem 276(14):10737-10744

178. Vekrellis K, Xilouri M, Emmanouilidou E, Rideout HJ, Stefanis L (2011) Pathological roles of alpha-synuclein in neurological disorders. Lancet Neurol 10(11):1015-1025. doi:10.1016/ S1474-4422(11)70213-7

179. Volpicelli-Daley LA, Luk KC, Patel TP, Tanik SA, Riddle DM, Stieber A, Meaney DF, Trojanowski JQ, Lee VM (2011) Exogenous alpha-synuclein fibrils induce Lewy body pathology leading to synaptic dysfunction and neuron death. Neuron 72(1):5771. doi:10.1016/j.neuron.2011.08.033

180. Wakabayashi K, Mori F, Tanji K, Orimo S, Takahashi H (2010) Involvement of the peripheral nervous system in synucleinopathies, tauopathies and other neurodegenerative proteinopathies of the brain. Acta Neuropathol 120(1):1-12. doi:10.1007/ s00401-010-0706-x

181. Wang J, Xu G, Slunt HH, Gonzales V, Coonfield M, Fromholt D, Copeland NG, Jenkins NA, Borchelt DR (2005) Coincident thresholds of mutant protein for paralytic disease and protein aggregation caused by restrictively expressed superoxide dismutase cDNA. Neurobiol Dis 20(3):943-952. doi:10.1016/j. nbd.2005.06.005

182. Wang ZY, Lian H, Cai QQ, Song HY, Zhang XL, Zhou L, Zhang YM, Zheng LF, Zhu JX (2014) No direct projection is observed from the substantia nigra to the dorsal vagus complex in the rat. J Parkinsons Dis 4(3):375-383. doi:10.3233/JPD-130279

183. Warren JD, Rohrer JD, Schott JM, Fox NC, Hardy J, Rossor MN (2013) Molecular nexopathies: a new paradigm of neurodegenerative disease. Trends Neurosci 36(10):561-569. doi:10.1016/j.tins.2013.06.007

184. Watts JC, Giles K, Oehler A, Middleton L, Dexter DT, Gentleman SM, DeArmond SJ, Prusiner SB (2013) Transmission of multiple system atrophy prions to transgenic mice. Proc Natl Acad Sci USA 110(48):19555-19560. doi:10.1073/pnas.1318268110

185. Waxman EA, Duda JE, Giasson BI (2008) Characterization of antibodies that selectively detect alpha-synuclein in pathological inclusions. Acta Neuropathol 116(1):37-46

186. Waxman EA, Giasson BI (2008) Molecular mechanisms of alpha-synuclein neurodegeneration. Biochim Biophys Acta 1792:616-624

187. Waxman EA, Giasson BI (2008) Specificity and regulation of casein kinase-mediated phosphorylation of alpha-synuclein. $\mathrm{J}$ Neuropathol Exp Neurol 67(5):402-416

188. Waxman EA, Giasson BI (2010) A novel, high-efficiency cellular model of fibrillar alpha-synuclein inclusions and the examination of mutations that inhibit amyloid formation. J Neurochem 113(2):374-388

189. Waxman EA, Mazzulli JR, Giasson BI (2009) Characterization of hydrophobic residue requirements for alpha-synuclein fibrillization. Biochemistry 48(40):9427-9436. doi:10.1021/ bi900539p

190. Westlund KN, Coulter JD (1980) Descending projections of the locus coeruleus and subcoeruleus/medial parabrachial nuclei in monkey: axonal transport studies and dopamine-beta-hydroxylase immunocytochemistry. Brain Res 2(3):235-264

191. Wood SJ, Wypych J, Steavenson S, Louis JC, Citron M, Biere AL (1999) Alpha-synuclein fibrillogenesis is nucleationdependent. Implications for the pathogenesis of Parkinson's disease. J Biol Chem 274(28):19509-19512

192. Xilouri M, Brekk OR, Stefanis L (2013) Alpha-synuclein and protein degradation systems: a reciprocal relationship. Mol Neurobiol 47(2):537-551. doi:10.1007/s12035-012-8341-2 
193. Yokota O, Tsuchiya K, Uchihara T, Ujike H, Terada S, Takahashi M, Kimura Y, Ishizu H, Akiyama H, Kuroda S (2007) Lewy body variant of Alzheimer's disease or cerebral type Lewy body disease? Two autopsy cases of presenile onset with minimal involvement of the brainstem. Neuropathology 27(1):21-35

194. Zarranz JJ, Alegre J, Gomez-Esteban JC, Lezcano E, Ros R, Ampuero I, Vidal L, Hoenicka J, Rodriguez O, Atares B, Llorens V, Gomez TE, del Ser T, Munoz DG, de Yebenes JG (2004)
The new mutation, E46K, of alpha-synuclein causes Parkinson and Lewy body dementia. Ann Neurol 55(2):164-173

195. Zhang W, Wang T, Pei Z, Miller DS, Wu X, Block ML, Wilson B, Zhang W, Zhou Y, Hong JS, Zhang J (2005) Aggregated alpha-synuclein activates microglia: a process leading to disease progression in Parkinson's disease. FASEB J 19(6):533-542

196. Zhu M, Fink AL (2003) Lipid binding inhibits alpha-synuclein fibril formation. J Biol Chem 278(19):16873-16877. doi:10.1074/jbc.M210136200 